\title{
ENTREPRENEURSHIP, GROWTH AND PRODUCTIVITY WITH BUBBLES
}

Lise Clain-Chamosset-Yvrard

Xavier Raurich

Thomas Seegmuller 
Title: Entrepreneurship, growth and productivity with bubbles

Abstract: Entrepreneurship, growth and total factor productivity are larger when there is a financial bubble. We explain these facts using a growth model with financial bubbles in which individuals face heterogeneous wages and returns on productive investment. The heterogeneity in the return of investment separates individuals between savers and entrepreneurs. Savers buy financial assets, which are deposits or a financial bubble. Entrepreneurs incur in a start-up cost and borrow to invest in productive capital. The bubble provides liquidities to credit-constrained entrepreneurs. These liquidities increase investment and entrepreneurship when the start-up cost is large enough, which explains that growth and entrepreneurship can be larger with bubbles. Finally, productivity can be larger when the bubble further increases the investment of more productive entrepreneurs. This can occur when the return of investment is correlated with wages.

JEL Codes: E22; E44; G12

Keywords: Bubble, entrepreneurship, growth, productivity

\section{Authors:}

Lise Clain-Chamosset-Yvrard

University of Lyon, Université

Lumière Lyon 2, GATE

Email: clain-

chamosset@gate.cnrs.fr
Xavier Raurich

University of Barcelona

Email:

xavier.raurich@ub.edu

\section{Email:}

thomas.seegmuller@univ-amu.fr

Date: February 2021 
Acknowledgements: Xavier Raurich thanks financial support from the Spanish Government and the European Union through grant RTI2018-093543-B-I00. Thomas Seegmuller thanks the financial support of the French National Research Agency Grant ANR-17-EURE-0020 and ANR-15-CE33- 0001-01. This paper benefits from the comments of Anpeng Lee and the participants of seminars at Dongbei University, University of Guanajuato and also of the participants in the workshop of the Spanish Macroeconomics Network. 


\section{Introduction}

After the great recession, there has been renewed interest in analyzing growth models with financial bubbles. However, the effect that bubbles may have on the number of entrepreneurs and their productivity has largely been ignored. ${ }^{1}$ The goal of this paper is to consider these effects to gain new insights into the consequences of financial bubbles for growth and productivity. To achieve this goal, we build a growth model with financial bubbles that not only explains facts obtained from aggregate data but also from firm-level data.

We distinguish two facts using aggregate data. First, Campbell (1999), among many others, show that asset price volatility is highly procyclical. We follow the literature on financial bubbles and interpret asset price growth as the result of a bubble and the reduction of asset prices as the result of a bubble burst. According to this interpretation, growth is larger when there is a bubble. Caballero et al. (2006) and Martin and Ventura (2012) provide convincing evidence on this relationship. Second, Basu, and Fernald (2001), Basu et al. (2006) and Field (2010) show that total factor productivity (TFP) is procyclical. ${ }^{2}$ Since bubbles are also procyclical, this second evidence implies that TFP is large when there is a bubble and declines when it bursts. This is consistent with findings obtained by Meza and Quintin (2005), Pratap and Urrutia (2012), Queralto (2011) and Tang (2017), who find that TFP fell during East Asian, Mexican and Argentine financial crises in the 1990s and in Spain during the Great Recession.

We also distinguish two facts using firm-level data. First, Koellinger and Thurik (2012) show that entrepreneurship is procyclical. ${ }^{3}$ Since bubbles are also procyclical, this finding implies that the number of entrepreneurs increases during a bubble and declines when it bursts. This has been confirmed by Klapper and Love (2011) and Tian (2018), who show that the number of entrepreneurs falls drastically during the Great Recession. Second, Bartelsman and Doms (2000), Lee and Mukoyama (2015) and Tian (2018) show that new firms are smaller and less productive than incumbents and that these differences are more pronounced in booms than in recessions. Therefore, periods with bubbles correspond to periods in which the number of firms increases, but these new firms are less productive and smaller in size.

\footnotetext{
${ }^{1}$ This is in contrast to the literature on firm dynamics, which has shown that entrepreneurship is an important channel through which financial development affects productivity. For instance, Midrigan and Xu (2014), Buera, et al. (2011) and Jeong and Townsend (2007) distinguish between the intensive and extensive margins of financial development and show that the effect on productivity is mostly explained by the extensive margin; that is, the change in the number of entrepreneurs and their productivity.

${ }^{2}$ Fernald and Wang (2016) confirm that TFP is procyclical, although they also show that after mid-1980s the TFP became less procyclical.

${ }^{3}$ Koellinger and Thurik (2012) show a positive correlation between entrepreneurship and deviations of GDP from trend for a cross-country panel of 22 OECD countries for the period 1972 to 2007. Bilbiie et al. (2012), Campbell (1998), and Clementi et al. (2016) show that in the US firms entry is procyclical, while exit is countercyclical.
} 
The literature on financial bubbles has mainly explained the facts obtained using aggregate data. This literature has studied the growth effects of bubbles since the seminal papers by Tirole (1985) and Grossman and Yanagawa (1993). In these papers, the introduction of a speculative asset without fundamental value, a financial bubble, reduces productive investment and growth. More recent literature has shown that if individuals are heterogeneous and face credit constraints then bubbles can promote growth, which is more in line with evidence. For instance, Fahri and Tirole (2012) consider a model with three period lived individuals and assume that productive investment can only be done in the second period of life. This implies that in every period there is heterogeneity among individuals of different age regarding their investment decisions. Since part of the labor income is generated in the first period of life whereas productive investment occurs in the second, the bubble, by increasing the savings devoted to the demand of financial assets, provides the liquidities needed to invest when individuals are credit constrained in the second period. This is the liquidity effect of the bubble that explains why growth is larger with bubbles. ${ }^{4}$ Another example of the liquidity effect is in Martin and Ventura (2012), who consider two groups of individuals differentiated by their return of productive investment. Those individuals with a large return invest and become entrepreneurs, whereas the rest are savers that accumulate financial assets. When entrepreneurs are credit constrained, the bubble promotes growth by providing the financial liquidity needed to invest. ${ }^{5}$

Some papers have also studied the effect of bubbles on TFP. In particular, Miao and Wang (2012) show that if bubbles increase investment of more productive entrepreneurs relative to less productive ones then TFP is larger with bubbles, which is in line with evidence. Hirano and Yanagawa (2017) obtain a similar conclusion in an endogenous growth model.

Very few papers consider the effect of bubbles on the number of entrepreneurs. One exception is Kunieda and Shibata (2016), who study an economy in which the returns of productive investment are individuallyspecific and follow a continuous distribution. Individuals compare these returns with the returns of financial assets to decide between being savers, who save only through financial assets, or entrepreneurs, who invest

\footnotetext{
${ }^{4}$ The literature distinguishes between two growth-enhancing roles of the bubbles. One is the liquidity role of the bubble: agents hold at the beginning of the period the bubble and sell it to increase their productive investment (Kocherlakota (2009), Farhi and Tirole (2012), Martin and Ventura (2012), Hirano and Yanagawa (2017)). The other one is the collateral role of the bubble: agents buy the bubble to increase their possibilities to borrow and use these loans to invest in capital (Kocherlakota (2009), Martin and Ventura (2016)). In Clain-Chamosset-Yvrad, et al. (2020) we show that in the absence of uncertainty both roles are identical. Accordingly, in this paper we do not distinguish them and we simply refer to this growth enhancing effect of the bubble as the liquidity effect.

${ }^{5}$ There are many other examples of models with bubbles and heterogeneous individuals. For instance, Bengui and Phan (2018) and Graczyk and Phan (2018) consider that individuals have different endowments, which separates individuals between borrowers and lenders. This distinction is also in Basco (2016) and in Kocherlakota (2009) in a model of infinitely lived agents. In contrast, Hillebrand (2018) distinguishes between three groups of individuals: savers, entrepreneurs and semi-entrepreneurs.
} 
in productive capital. Since the bubble increases the savings devoted to the demand of financial assets, it rises the return of these assets. As a consequence, the bubble reduces the number of entrepreneurs. ${ }^{6}$

We contribute to this literature by showing that the aforementioned four facts can be explained as the result of the transition between a bubbly and a bubbleless steady state of an overlapping generations (OLG) model with the following characteristics. First, as in Fahri and Tirole (2012) and Clain-Chamosset-Yvrad et al. (2020), we introduce the liquidity effect of the bubble by assuming that individuals can invest in productive capital only in the second period of life, whereas part of the labor income is obtained in the first period. In the first period, individuals save or borrow through two different financial assets: a deposit (or a credit) and a financial bubble. In the second period, individuals face a borrowing constraint that limits investment. More precisely, to borrow they must use the financial asset and productive capital as collateral. Second, as in Kunieda and Shibata (2016), there is a continuous distribution of abilities in the population. These abilities are an individual-specific productivity shock that determines the return of productive investment. Third, as in Martin and Ventura (2012), Kunieda and Shibata (2016), Hirano and Yanagawa (2017), among many others, these heterogeneous returns separate individuals between entrepreneurs and savers. Forth, we assume that abilities not only determine the productivity of individuals as entrepreneurs but also as workers. As a result, wages are heterogeneous in the first two periods of life. Finally, we assume that individuals incur a start-up cost to be entrepreneurs. The introduction of this cost and wage heterogeneity are the novelties of this model. We show that they are crucial to explain the aforementioned facts.

The economy can converge to two different steady states: a bubbly steady state in which financial assets are deposits and the speculative asset, and a bubbleless steady state in which the only financial asset is the deposit. We show that the return of financial assets is larger in the equilibrium with bubbles, which is a consequence of the larger demand of financial assets in this equilibrium. We also show that if a bubbly steady state exists then the return of financial assets equals the growth rate in this steady state and it is lower in the bubbleless steady state. These results coincide with the ones obtained by Tirole (1985) and Grossman and Yanagawa (1993) in models in which individuals that belong to the same generation are identical. Therefore, we show that these classical results remain with heterogeneous individuals.

We use the comparison between steady states to study the effect of the bubble on the composition of the population between savers and entrepreneurs, on growth and on productivity. Two opposite mechanisms determine the effect of the bubble on the composition of the population. On the one hand, in a bubbly economy the return of financial assets is larger, which implies that more individuals choose to be savers. On the other hand, the liquidities provided by the bubble make adult individuals wealthier, which facilitates

\footnotetext{
${ }^{6}$ Kunieda (2008) considers the same mechanism in the context of an OLG model and Kunieda (2014) also introduces this mechanism to study the effect of bubbles on growth in a model of perpetual youth.
} 
that more individuals can afford the start-up cost. Therefore, the number of entrepreneurs is larger in the bubbly economy when this cost mechanism dominates. Moreover, we show that these new entrepreneurs are less productive and invest less than existing entrepreneurs, which is in line with firm level evidence. ${ }^{7}$

We also show that the bubble affects growth through three distinct effects: the liquidity, leverage and composition effects of the bubble. First, as in Fahri and Tirole (2012), the bubble provides liquidities to adult credit constrained entrepreneurs that then increase productive investment. Thus, the liquidity effect promotes growth. Second, the larger return of financial assets in the bubbly economy reduces the amount of credit that can be obtained using productive investment as collateral. As a result, productive investment decreases. This is the leverage effect that reduces growth. Finally, the composition effect of the bubble is a contribution of this paper. A larger number of entrepreneurs increases capital accumulation and growth. Therefore, the composition effect promotes growth when the bubble increases the number of entrepreneurs.

We finally show that the previous three effects also modify TFP. The composition effect decreases productivity when the number of entrepreneurs increases, since new entrepreneurs have lower productivities. The leverage effect reduces TFP because the increase in the return of financial assets causes a larger decline of the investment of more productive entrepreneurs. Finally, the liquidity effect of the bubble increases TFP when the productivity of investment is more correlated with the wages in the first period of life than with the wages in the second period. When this happens, the bubble provides more liquidities to more productive entrepreneurs. As a consequence, it further increases the investment of highly productive entrepreneurs, which explains that the liquidity effect increases TFP.

The correlation between wages in the first period of life and the return of investment in the second period is related to findings in the literature that studies the effect of financial development on growth and TFP. This literature interprets financial development as access to external financing that, together with self-financing, is used to invest (see Cooley and Quadrini, 2001; Midrigan and Xu, 2014). In this literature, self-financing substitutes external financing. As a result, Moll (2014) shows that external financing cause a smaller increase in TFP when idiosyncratic shocks are persistent, since more productive entrepreneurs have access to larger self-financing. We also analyze how the interaction between the persistence of idiosyncratic shocks and external financing affects TFP. In our model, the persistence of shocks is measured by the correlation between wages of the young and investment productivity of the adult, self-financing corresponds to the savings of the young individuals who will be entrepreneurs in the following period and we consider two sources of external financing: credit and the bubble. The bubble introduces significant differences. Unlike Moll (2014), we show that when this correlation is large, the external financing, introduced in our framework

\footnotetext{
${ }^{7}$ This result is related to Aghion et al. (2019) that shows that better credit access allows less efficient firms to remain longer on the market.
} 
by the bubble, positively affects TFP. The reason for this different finding is that the bubble increases the returns of the savings of the young individuals and, hence, it enlarges the effect of self-financing on investment. Thus, self-financing complements the bubble, whereas it substitutes credit.

We conclude that the bubble can increase the number of entrepreneurs, growth and TFP, even though new entrepreneurs are less productive. Therefore, this model not only explains the facts obtained using aggregate data, but also the facts obtained using firm level data. As a consequence, we include the composition effect in the analysis of the growth and productivity effects of bubbles, focusing on the extensive margin of the bubble.

This paper is organized as follows. Section 2 presents the model. Section 3 characterizes the equilibrium. Section 4 analyzes the effect of bubbles on entrepreneurship, productivity and growth. Concluding remarks are provided in Section 5, while some technical details are relegated to an Appendix.

\section{Model}

We consider a discrete time overlapping generations model $(t=1,2, \ldots)$ with firms, entrepreneurs and savers.

\subsection{Production}

We assume that entrepreneurs produce a homogenous good with the same constant returns to scale technology. As a result, production is fully characterized using an aggregate production function that relates final output, $y_{t}$, with efficiency units of labor, $l_{t}$, and aggregate capital, $k_{t}$. An externality associated to the average capital to labor ratio, $\bar{a}_{t}$, increases labor productivity. Therefore, the aggregate production function is:

$$
y_{t}=F\left(k_{t}, \bar{a}_{t} l_{t}\right)
$$

This production function has the usual neoclassical properties; that is, it is a strictly increasing and concave production function satisfying the Inada conditions and is homogeneous of degree one with respect to its two arguments. Profit maximization under perfect competition implies that the wage $w_{t}$ per efficiency unit and the return of capital $q_{t}$ are given by:

$$
\begin{gathered}
w_{t}=F_{2}\left(k_{t}, \bar{a}_{t} l_{t}\right) \bar{a}_{t}, \\
q_{t}=F_{1}\left(k_{t}, \bar{a}_{t} l_{t}\right) .
\end{gathered}
$$

We will consider only symmetric equilibria for which $\bar{a}_{t}=a_{t}$, where $a_{t} \equiv k_{t} / l_{t}$. Using (1) and (2), we 
deduce that the wage per efficiency unit and the return of capital at an equilibrium satisfy:

$$
\begin{gathered}
w_{t}=(1-s) A a_{t}, \\
q_{t}=s A,
\end{gathered}
$$

where $s \equiv F_{1}(1,1) / F(1,1) \in(0,1)$ is the capital income share and $A \equiv F(1,1)>0$.

\subsection{Individuals}

The economy is populated by individuals $i \in[0, N]$ that live for three periods: young, adult and old. We assume that the mass of individuals in each generation $N$ is constant.

Young and adult individuals work and obtain wages $w_{y, t}^{i}$ and $w_{a, t+1}^{i}$, respectively. Young individuals consume $c_{1, t}^{i}$ and save using two different financial assets: a speculative asset, $b_{1, t}^{i}$, with return $R_{1, t+1}$ and a deposit, $d_{1, t}^{i}$, with return $R_{d, t+1}$. Adult individuals consume $c_{2, t+1}^{i}$, may invest $\kappa_{t+2}^{i}$ in productive capital and save $b_{2, t+1}^{i}$ in the speculative asset and $d_{2, t+1}^{i}$ in the deposit. Individuals that invest in productive capital are entrepreneurs and obtain a return of productive investment that is individually specific and equal to $q_{t+2}^{i} .{ }^{8}$ Capital totally depreciates after a period. The return of the speculative asset purchased by adult individuals is $R_{2, t+2}$, which is a priory different from the return of the speculative asset purchased by young individuals. These speculative assets, that are supplied in a fixed amount, are financial bubbles when their aggregate value is positive. Since their fundamental value is zero, their return coincides with the growth of its price. Finally, old individuals do not work, obtain the return of the different investments made when adult and consume $c_{3, t+2}^{i}$. Accordingly, the budget constraints of the young, adult and old individuals are, respectively:

$$
\begin{gathered}
c_{1, t}^{i}+d_{1, t}^{i}+b_{1, t}^{i}=w_{y, t}^{i}, \\
c_{2, t+1}^{i}+\kappa_{t+2}^{i}+d_{2, t+1}^{i}+b_{2, t+1}^{i}=w_{a, t+1}^{i}+R_{d, t+1} d_{1, t}^{i}+R_{1, t+1} b_{1, t}^{i}, \\
c_{3, t+2}^{i}=q_{t+2}^{i} \kappa_{t+2}^{i}+R_{d, t+2} d_{2, t+1}^{i}+R_{2, t+2} b_{2, t+1}^{i} .
\end{gathered}
$$

The financial assets are used to borrow when they take negative values. A negative value of the speculative asset implies that individuals short sell this asset, whereas a negative deposit is a credit. Therefore, adult individuals that borrow have access to two different sources of external financing: the credit and the bubble. These individuals face the following constraint:

$$
-R_{d, t+2} d_{2, t+1}^{i} \leq R_{2, t+2} b_{2, t+1}^{i}+\theta q_{t+2}^{i} \kappa_{t+2}^{i} .
$$

\footnotetext{
${ }^{8}$ This individually specific return of investment is consistent with recent evidence that shows that the return of investment increases with the wealth of the investor (see Fagereng, et al., 2020).
} 
This credit constraint ensures a strictly positive wealth in the last period of life and implies that the cost of the credit, $-R_{d, t+2} d_{2, t+1}^{i}$, is limited by the value of the bubble in the last period and by the return of productive investment. ${ }^{9}$ Therefore, both the bubble and a fraction $\theta \in[0,1)$ of productive investment are used as collateral. The parameter $\theta$ measures the degree of pledgeability of productive investment and, hence, it is a measure of financial development.

The return of the financial assets has different interpretations. It is an interest factor for deposits, while it is the growth of the price for the speculative asset. Despite this different interpretation, from the budget and credit constraints we observe that the financial assets are perfect substitutes and, therefore, their returns coincide, i.e. $R_{d, t+1}=R_{1, t+1}=R_{2, t+1}$. We denote by $R_{t+1}$ this common return of financial assets. Therefore, both sources of external financing are identical for the individuals. However, since the aggregate supply of these two financial assets are different, the introduction of the bubble modifies individuals decisions through general equilibrium effects.

Preferences of an individual $i$ born in period $t$ are represented by the following utility function:

$$
\alpha \ln \left(c_{1, t}^{i}\right)+\beta \ln \left(c_{2, t+1}^{i}-f_{t+1}^{i}\right)+\gamma \ln \left(c_{3, t+2}^{i}\right),
$$

where $\alpha, \beta$ and $\gamma$ are positive preference parameters that satisfy $\alpha+\beta+\gamma=1$, and $f_{t+1}^{i}$ is a start-up cost that individuals must pay to be entrepreneurs.

Adult individuals that decide to be entrepreneurs spend time searching for productive investment opportunities, which introduces a start-up cost that takes the form of a time cost. This time cost reduces leisure time and, therefore, causes a utility loss. Since it is a time cost, we assume that it is proportional to the wage of adult individuals, $w_{a, t+1}^{i}$. Therefore, the start-up cost is $f_{t+1}^{i}=\xi w_{a, t+1}^{i}>0$ if the individual is an entrepreneur, whereas $f_{t+1}^{i}=0$ if she is not. ${ }^{10}$ The parameter $\xi \in(0,1)$ is the start-up cost rate that measures the fraction of time spend searching for investment opportunities. The additive form of the utility function used to introduce the start-up cost has the advantage that the cost can also be interpreted as a reduction of the adult individuals' employment or as a cost in terms of consumption goods. In fact, the solution of the individuals problem is identical under these different interpretations. ${ }^{11}$ Finally, it is important to underline

\footnotetext{
${ }^{9}$ A similar credit constraint was introduced by Martin and Ventura (2016), and by Kocherlakota (2009) in the particular case in which $\theta=0$.

${ }^{10}$ Poschke (2013) among many other have also assumed that the cost of becoming an entrepreneurs is an opportunity cost in terms of forgone wages. In Chatterjee et al. (1993) and many others, this opportunity cost directly causes a utility loss.

${ }^{11}$ We have interpreted the start-up cost as a reduction in the time devoted to leisure. However, we could have also interpreted it as a reduction in the time available to work or as an expenditure. To see that the solution of the consumers' problem is identical under these different interpretations of the cost, it is enough to define consumption when adult as $\widetilde{c}_{2, t+1}^{i}=c_{2, t+1}^{i}-f_{t+1}^{i}$. Rewriting the adults' budget constraint using $\widetilde{c}_{2, t+1}^{i}$, it is immediate to see that adults' labor income is $(1-\xi) w_{a, t+1}^{i}$, which is consistent with the cost implying a reduction in the time devoted to work. It is also consistent with an increase in the
} 
that the start-up cost does not depend on the amount of entrepreneurs' investment. As a result, this cost introduces a discontinuity in the utility function.

We close the introduction of the model by describing heterogeneity. We assume that individuals are heterogeneous in their innate abilities, $\delta^{i}$. In every generation, $\delta^{i}$ follows a time invariant and continuously differentiable cumulative distribution function $F\left(\delta^{i}\right)$ with support $\delta^{i} \in\left(\delta_{\min }, \delta_{\max }\right)$. These abilities are an individual-specific productivity shock that determines the return of productive investment and wages. On the one hand, an individual $i$ that invests $\kappa_{t+2}^{i}$ units when adult obtains $\delta^{i} \kappa_{t+2}^{i}$ units of productive capital when old. Therefore, the return of investment is $q_{t+2}^{i}=q_{t+2} \delta^{i}$, where $q_{t+2}=s A$ is the constant return of capital. It follows that the return of investment is perfectly correlated with abilities.

On the other hand, wages of the young individuals satisfy: $w_{y, t}^{i}=\left(\delta^{i}\right)^{v_{1}} w_{t}$, where $w_{t}$ is the wage per efficiency unit, $\left(\delta^{i}\right)^{v_{1}}$ measures the efficiency units of a young individual $i$ and $v_{1} \in[0,1]$ measures the correlation between wages of young individuals and abilities. Since abilities are perfectly correlated with the return of productive investment, $v_{1}$ also measures the correlation between this return and the wages of young individuals. Adult individuals wages are also an increasing function of abilities satisfying: $w_{a, t+1}^{i}=\phi\left(\delta^{i}\right)^{v_{2}} w_{t+1}$, where $\phi\left(\delta^{i}\right)^{v_{2}}$ measures the efficiency units of labor of an adult individual $i$. The parameter $\phi \geq 1$ measures the common increase of wages in adulthood associated to accumulated skills and $v_{2} \geq 0$ measures the correlation between wages of adult individuals and the return of investment. Since young individuals do not benefit from accumulated skills, we assume that their wages are more correlated with innate abilities; i.e. $v_{1} \geq v_{2}$. Assumption A groups all these assumptions.

Assumption A. $v_{j} \in[0,1], j=1,2, v_{1} \geq v_{2}, \phi \geq 1$ and $\delta_{\min }=1$.

As follows from Assumption A, we also assume that $\delta_{\min }=1$, which implies that the return of investment of the individual with the lowest ability equals the return of capital and this individual is endowed with one efficiency unit of labor when young and $\phi$ units when adult.

\subsection{Individuals' decisions}

To characterize the individual's decisions on both consumption and investment, we must take into account that the start-up cost introduces a discontinuity in the utility function. Therefore, we solve the individuals' problem by backward induction following a two step procedure. First, we obtain the individuals' optimal demands of both consumption and assets that maximize (9) subject to the budget constraints (5)-(7), the credit constraint (8) and a non-negativity constraint on investment, $\kappa_{t+2}^{i} \geq 0$. In solving this maximization problem, we distinguish between two groups of individuals: savers and entrepreneurs. Savers are those expenditures of $\xi w_{a, t+1}^{i}$. 
individuals that only invest in financial assets, whereas entrepreneurs are those individuals that pay the start-up cost and invest in productive capital. In a second step, we use the individuals' consumption demands to obtain the indirect utility function of both savers and entrepreneurs. We compare these indirect utility functions to determine the amount of entrepreneurs. Details are given in Appendix A.

We consider first the optimal decisions of savers. They are not credit constrained and their consumption decisions are determined by the following first order conditions:

$$
\begin{gathered}
c_{2, t+1}^{i, S}=(\beta / \alpha) R_{t+1} c_{1, t}^{i, S}, \\
c_{3, t+2}^{i, S}=(\gamma / \beta) R_{t+2} c_{2, t+1}^{i, S},
\end{gathered}
$$

where $c_{1, t}^{i, S}, c_{2, t+1}^{i, S}$ and $c_{3, t+2}^{i, S}$ denote, respectively, the consumption of young, adult and old savers. ${ }^{12}$ Savers only invest in financial assets, the deposit and the bubble, which are perfect substitutes. We denote the financial assets owned by young and adult savers as $x_{1, t}^{i, S}=b_{1, t}^{i, S}+d_{1, t}^{i, S}$ and $x_{2, t+1}^{i, S}=b_{2, t+1}^{i, S}+d_{2, t+1}^{i, S}$. We easily obtain from the budget constraints, (5)-(7), and from the first order conditions, (10) and (11), that financial assets satisfy:

$$
\begin{gathered}
x_{1, t}^{i, S}=(\beta+\gamma) w_{y, t}^{i}-\alpha \frac{w_{a, t+1}^{i}}{R_{t+1}}, \\
x_{2, t+1}^{i, S}=\gamma\left(R_{t+1} w_{y, t}^{i}+w_{a, t+1}^{i}\right) .
\end{gathered}
$$

We next consider the optimal decisions of entrepreneurs. They are credit constrained and their consumption and investment decisions are determined by the following first order conditions:

$$
\begin{gathered}
c_{2, t+1}^{i, E}-f_{t+1}^{i}=(\beta / \alpha) R_{t+1} c_{1, t}^{i, E}, \\
c_{3, t+2}^{i, E}=(\gamma / \beta) \psi_{t+2}^{i} q_{t+2}^{i}\left(c_{2, t+1}^{i, E}-f_{t+1}^{i}\right),
\end{gathered}
$$

where $c_{1 t}^{i, E}, c_{2 t+1}^{i, E}$ and $c_{3 t+2}^{i, E}$ denote, respectively, the consumption of young, adult and old entrepreneurs and $\psi_{t+2}^{i}=(1-\theta) /\left(1-\theta q_{t+2}^{i} / R_{t+2}\right)$. Since $\theta<1, \psi_{t+2}^{i}>0$ requires $q_{t+2}^{i}<R_{t+2} / \theta$. We define the financial assets owned by young and adult entrepreneurs as $x_{1, t}^{i, E}=b_{1, t}^{i, E}+d_{1, t}^{i, E}$ and $x_{2, t+1}^{i, E}=b_{2, t+1}^{i, E}+d_{2, t+1}^{i, E}$ and we use the binding credit constraint, the budget constraints (5)-(7) and the first order conditions (14) and (15) to obtain financial assets:

$$
\begin{gathered}
x_{1, t}^{i, E}=(\beta+\gamma) w_{y, t}^{i}-\alpha \frac{w_{a, t+1}^{i}-f_{t+1}^{i}}{R_{t+1}} \\
x_{2, t+1}^{i, E}=-\left(\frac{\theta \gamma q_{t+2}^{i}}{R_{t+2}}\right)\left(\frac{1}{1-\theta q_{t+2}^{i} / R_{t+2}}\right)\left(R_{t+1} w_{y, t}^{i}+w_{a, t+1}^{i}-f_{t+1}^{i}\right),
\end{gathered}
$$

\footnotetext{
${ }^{12}$ The super index $S$ identifies the optimal decisions of savers, whereas the super index $E$ identifies the optimal decisions of entrepreneurs.
} 
and the amount of productive investment

$$
\kappa_{t+2}^{i}=\gamma\left(\frac{1}{1-\theta q_{t+2}^{i} / R_{t+2}}\right)\left(R_{t+1} w_{y, t}^{i}+w_{a, t+1}^{i}-f_{t+1}^{i}\right)
$$

Entrepreneurs are not credit constrained when young and, therefore, they use the financial assets to smooth consumption between their first two periods of life. Instead, they are credit constrained when adult. Therefore, they smooth consumption between the second and third periods of life using productive investment. Since the return of this investment is individually specific, entrepreneurs are heterogeneous in the amount consumed when old even if wages are identical among individuals of the same generation. This is an important difference with respect to savers. A second difference is the start-up cost paid by entrepreneurs. It reduces entrepreneurs' productive investment. Finally, another difference is that adult savers use financial assets to save and, instead, adult entrepreneurs use them to borrow to finance productive investment.

The first term in (18) is the multiplier of productive investment, which takes into account that each unit invested has a multiplier effect that results into $1 /\left(1-\theta q_{t+2}^{i} / R_{t+2}\right)$ units finally invested. To be positive and finite, we assume that $q_{t+2}^{i}<R_{t+2} / \theta$ for all individuals, which introduces an upper bound on the value of abilities. Since the amount of collateral depends on the return of investment and it is larger for more productive entrepreneurs, these entrepreneurs obtain a larger credit and invest a larger amount in productive capital when $\theta>0$. This explains that the investment multiplier of more productive entrepreneurs is larger. Therefore, the interaction between the credit constraint and the heterogeneous returns of productive investment is one determinant of the different amounts invested by entrepreneurs. The other determinant is labor income differences. As follows from (18), investment in productive capital increases with the present value of labor income net of start-up costs in the second period of life. Finally, since entrepreneurs with larger innate abilities benefit from a larger investment multiplier and have larger wages, they invest more and therefore own larger firms.

We next consider the individual decision between being a saver or an entrepreneur, which is based on the comparison between the indirect utility function of savers and entrepreneurs. In Appendix A, we show that an individual that is adult in period $t$ obtains a larger utility as entrepreneur when $q_{t+1}^{i}>R_{t+1} / \omega_{t}^{i}$, where

$$
\omega_{t}^{i}=\left(1-\frac{f_{t}^{i}}{w_{a, t}^{i}+R_{t} w_{y, t-1}^{i}}\right)^{\frac{1}{\gamma}}(1-\theta)+\theta .
$$

Since $f_{t}^{i} \leq w_{a, t}^{i}$ and $\theta<1$, it follows that $\omega_{t}^{i} \in(\theta, 1)$ when $f_{t}^{i}>0$. Therefore, an individual becomes an entrepreneur only when the return of productive investment is strictly larger than the return of financial assets; that is, $q_{t+1}^{i}>R_{t+1}$. In contrast, in the absence of a start-up cost, $\omega_{t}^{i}=1$ and an individual with $q_{t+1}^{i}=R_{t+1}$ is indifferent between being an entrepreneur or a saver. We reached the same conclusion if we consider the limiting case in which the degree of pledgeability equals one. Therefore, the interaction between 
the start-up cost and the financial frictions explain that $q_{t+1}^{i}>R_{t+1}$. Clearly, a larger start-up cost or a smaller degree of pledgeability increase the minimum return of productive investment necessary to be an entrepreneur and, hence, reduce the number of entrepreneurs.

Using (3) and (19), we rewrite $\omega_{t}^{i}$ as the following increasing function of both $\delta^{i}$ and of the ratio between the interest factor and the growth factor, $z_{t} \equiv R_{t} / g_{t}$, where $g_{t} \equiv a_{t} / a_{t-1}$ :

$$
\omega_{t}^{i} \equiv \omega\left(\delta^{i}, z_{t}\right)=\left(1-\frac{\xi \phi\left(\delta^{i}\right)^{v_{2}}}{\phi\left(\delta^{i}\right)^{v_{2}}+\left(\delta^{i}\right)^{v_{1}} z_{t}}\right)^{\frac{1}{\gamma}}(1-\theta)+\theta
$$

As shown in (19), the effect of the start-up cost on $\omega_{t}^{i}$ is determined by the ratio $f_{t}^{i} /\left(w_{a, t}^{i}+R_{t} w_{y, t-1}^{i}\right)$, which measures the cost as a fraction of the present value labor income in the second period of life. Since young individuals obtain wages in the previous period, this ratio decreases with the interest factor and increases with the growth rate of wages, which in this model coincides with the growth rate of $a_{t}$. As a result, the ratio between the start-up cost and the present value of labor income decreases with the ratio $z_{t}$, which explains that $\omega_{t}^{i}$ increases with $z_{t}$. In other words, the ratio $z_{t}$ determines the effect of first period wages on the net present value of labor income in the second period of life. Hence, when $z_{t}$ increases, the labor income in the second period of life increases and the cost as a fraction of this income decreases.

To determine the number of entrepreneurs, we define by $\bar{\delta}_{t}$ the ability of the marginal individual that in period $t$ is indifferent between investing in financial assets or in productive capital. We obtain $\bar{\delta}_{t}$ from the solution of the following equation:

$$
\bar{\delta}_{t}=\frac{R_{t+1}}{\omega\left(\bar{\delta}_{t}, z_{t}\right) s A} .
$$

Note that those adult individuals with $\delta^{i}>\bar{\delta}_{t}$ satisfy $q_{t+1}^{i}>R_{t+1} / \omega_{t}^{i}$ and, therefore, are entrepreneurs. The rest are savers. Therefore, the fraction of adult entrepreneurs in $t, \lambda_{t}$, satisfies $\lambda_{t}=1-F\left(\bar{\delta}_{t}\right)$.

Using (20) and (21), we obtain that $\bar{\delta}_{t}=\widetilde{\delta}\left(R_{t+1}, z_{t}\right)$ is an increasing function of $R_{t+1}$ and a decreasing function of the ratio $z_{t}$ when $\xi>0$. Since the fraction of entrepreneurs decreases with $\bar{\delta}_{t}$, we obtain that this fraction is a decreasing function of $R_{t+1}$ and an increasing function of the ratio $z_{t}$ when $\xi>0$. A larger return of financial assets, $R_{t+1}$, decreases the number of entrepreneurs, since more individuals obtain a larger utility when they only invest in financial assets. In contrast, an increase in the ratio $z_{t}$ makes adult individuals wealthier and, as a consequence, more individuals find affordable the cost and become entrepreneurs. This positive effect of wealth on entrepreneurship is well-known and supported by empirical evidence (see, for instance, Quadrini, 2009).

At this point, we introduce constraints on the domain of the distribution in order to ensure that the equilibrium is well-defined with a positive number of both savers and entrepreneurs. In particular, we assume that $\delta_{\max }<R_{t+1} /(\theta s A)$ so that the multiplier of investment is positive and finite for all individuals 
and we also assume that $\bar{\delta}_{t} \in\left(\delta_{\min }, \delta_{\max }\right)$ so that $\lambda_{t} \in(0,1)$. These assumptions are rewritten as constraints on the return of the financial assets in the following assumption:

Assumption B. $R_{t+1}>\max \left\{\omega\left(\delta_{\min }, z_{t}\right) s A \delta_{\min }, \theta s A \delta_{\max }\right\}=\theta s A \delta_{\max }$ with $\omega\left(\delta_{\min }, z_{t}\right) \delta_{\min }<\theta \delta_{\max }$ and $R_{t+1}<\omega\left(\delta_{\max }, z_{t}\right) s A \delta_{\max }$.

In the following section, we guarantee that this assumption is satisfied at all steady state equilibria.

\section{Equilibrium}

\subsection{Intertemporal equilibrium}

We determine the equilibrium using the market clearing conditions for productive capital and financial assets. The first one implies that the firms' aggregate demand of productive capital in period $t+1, k_{t+1}$, equals the aggregate supply of productive capital that results from the aggregation of the product between investment productivity, $\delta^{i}$, and investments, $\kappa_{t+1}^{i}$, of each entrepreneur. Therefore, the market clearing condition in period $t+1$ is $k_{t+1}=\int_{\bar{\delta}_{t}}^{\delta_{\max }} \delta^{i} \kappa_{t+1}^{i} N f\left(\delta^{i}\right) d \delta^{i}$, where $f\left(\delta^{i}\right)$ is the density function. Using (3) and (18), we rewrite the market clearing condition for productive capital as

$$
k_{t+1}=\gamma N w_{t} \tau_{t},
$$

where $\tau_{t} \equiv \widetilde{\tau}\left(\bar{\delta}_{t}, R_{t+1}, z_{t}\right)$ satisfies:

$$
\tau_{t}=\int_{\bar{\delta}_{t}}^{\delta_{\max }} \frac{\delta^{i}}{1-\theta s A \delta^{i} / R_{t+1}}\left[z_{t}\left(\delta^{i}\right)^{v_{1}}+(1-\xi) \phi\left(\delta^{i}\right)^{v_{2}}\right] f\left(\delta^{i}\right) d \delta^{i} .
$$

Equation (22) indicates that capital at $t+1$ depends on the present value of labor income of all entrepreneurs at period $t$, taking into account that this labor income affects capital accumulation depending on the productivity of investment and the investment multiplier of each entrepreneur. More precisely, capital depends on the product between the wage per efficiency unit and $\tau_{t}$, which is a measure of the aggregate efficiency units of labor of entrepreneurs that takes into account the productivity of investment and the investment multiplier. The term of $\tau_{t}$ inside the square brackets amounts for the efficiency units of labor at young and adult ages. Young individuals efficiency units are multiplied by the ratio $z_{t}$, because young individuals obtain labor income one period before individuals invest in capital and adult individuals efficiency units are multiplied by $1-\xi$ to substract the start-up cost.

From (23), it is immediate to see that $\tau_{t}$ decreases with $\bar{\delta}_{t}$ and $R_{t+1}$ and increases with $z_{t}$. The intuition is quite immediate. First, an increase in $\bar{\delta}_{t}$ reduces the number of entrepreneurs and, as a result, capital accumulation decreases. Second, an increase in $R_{t+1}$ reduces the investment multiplier when $\theta>0$, which 
also reduces capital accumulation. Finally, since young individuals obtain wages in the first period of life, adult individuals are wealthier when $z_{t}$ increases, which explains the positive effect of this ratio on capital accumulation.

It is convenient to rewrite (22) in terms of $R_{t+1}$ and $z_{t}$. To this end, we use the definition of $a_{t}$ to obtain that $a_{t+1}=k_{t+1} / l_{t+1}$, where $l_{t+1}$ are the total efficiency units of employment that satisfy $l_{t+1}=$ $N\left(\chi^{1}+\phi \chi^{2}\right)$, where:

$$
\chi^{j}=\int_{\delta_{\min }}^{\delta_{\max }}\left(\delta^{i}\right)^{v_{j}} f\left(\delta^{i}\right) d \delta^{i}, j=1,2 .
$$

We use the definitions of $a_{t+1}$ and of the ratio $z_{t}$ and equations (3) and (22) to obtain that the market clearing condition for productive capital satisfies:

$$
R_{t+1}=\frac{A \gamma(1-s)}{\chi^{1}+\phi \chi^{2}} z_{t+1} \tau_{t}
$$

We next obtain the market clearing condition for financial assets. To this end, we first use (3), (12) and (13) to deduce that the aggregate value of the financial assets owned by young and adult savers is:

$$
\begin{gathered}
x_{1 t}^{S}=(1-s) A N a_{t}\left((\beta+\gamma) \eta_{t+1}^{1}-\frac{\alpha \phi}{z_{t+1}} \eta_{t+1}^{2}\right), \\
x_{2 t+1}^{S}=\gamma(1-s) A N a_{t+1}\left(z_{t+1} \eta_{t+1}^{1}+\phi \eta_{t+1}^{2}\right),
\end{gathered}
$$

where

$$
\eta_{t+1}^{j} \equiv \widetilde{\eta}^{j}\left(\bar{\delta}_{t+1}\right)=\int_{\delta_{\min }}^{\bar{\delta}_{t+1}}\left(\delta^{i}\right)^{v_{j}} f\left(\delta^{i}\right) d \delta^{i}, j=1,2
$$

measures the aggregate efficiency units of labor of savers, which are an increasing function of $\bar{\delta}_{t+1}$.

Using (3), (16) and (17), we obtain that the aggregate value of the financial assets owned by young and adult entrepreneurs is:

$$
\begin{gathered}
x_{1 t}^{E}=(1-s) A N a_{t}\left((\beta+\gamma) \pi_{t+1}^{1}-\alpha \frac{(1-\xi) \phi \pi_{t+1}^{2}}{z_{t+1}}\right), \\
x_{2 t+1}^{E}=-\theta \gamma(1-s) A N s A \frac{a_{t+1} \tau_{t+1}}{R_{t+2}}
\end{gathered}
$$

where

$$
\pi_{t+1}^{j} \equiv \widetilde{\pi}^{j}\left(\bar{\delta}_{t+1}\right)=\int_{\bar{\delta}_{t+1}}^{\delta_{\max }}\left(\delta^{i}\right)^{v_{j}} f\left(\delta^{i}\right) d \delta^{i}, j=1,2,
$$

measures the aggregate efficiency units of labor of entrepreneurs, which are a decreasing function of $\bar{\delta}_{t+1}$. Observe that $\widetilde{\pi}^{j}\left(\bar{\delta}_{t+1}\right)+\widetilde{\eta}^{j}\left(\bar{\delta}_{t+1}\right)=\chi^{j}$.

We define the aggregate value of financial assets owned by individuals at period $t$ as $\Psi_{t}=x_{1 t}^{E}+x_{1 t}^{S}+$ $x_{2 t}^{E}+x_{2 t}^{S}$. Using (25)-(28), we obtain

$$
\Psi_{t}=(1-s) A N a_{t} \Delta_{t}
$$


where

$$
\Delta_{t}=(\beta+\gamma) \chi^{1}-\frac{\alpha \phi \chi^{2}}{z_{t+1}}+\frac{\alpha \xi \phi \pi_{t+1}^{2}}{z_{t+1}}+\gamma\left(z_{t} \eta_{t}^{1}+\phi \eta_{t}^{2}\right)-\frac{\theta \gamma s A \tau_{t}}{R_{t+1}} .
$$

The market clearing condition for financial assets depends on the type of financial asset. In a bubbleless equilibrium, $b_{1, t}^{i}=b_{2, t}^{i}=0$ and the financial assets are only deposits and credits. Since the aggregate value of deposits equals the aggregate value of credits in every period, the market clearing condition implies that the aggregate value of the financial assets owned by individuals is zero in every period; that is $\Psi_{t}=0$ or, equivalently, $\Delta_{t}=0$. In contrast, in a bubbly equilibrium, financial assets include the bubble and also deposits and credits. The equality between the aggregate values of deposits and credits implies that the aggregate value of the financial assets equals the value of the bubble, which is positive in a bubbly equilibrium; that is $\Psi_{t}=\int_{\delta_{\min }}^{\delta_{\max }} b_{1, t}^{i} d \delta^{i}+\int_{\delta_{\min }}^{\delta_{\max }} b_{2, t}^{i} d \delta^{i}>0$. In this case, the market clearing condition states that the value of the bubble purchased at $t+1$ by young and adult individuals equals the value of the bubble that in period $t+1$ adult and old individuals sell; that is,

$$
\Psi_{t+1}=R_{t+1} \Psi_{t}
$$

Since we assume that the supply of the bubble is fixed, equation (30) implies that the growth of the bubble equals its return, $R_{t+1}$. Using the definition of the ratio $z_{t}$, this market clearing condition can be rewritten in a more convenient way as

$$
\Delta_{t+1}=z_{t+1} \Delta_{t}
$$

The aggregate value of financial assets shows the difference between the two sources of external financing. When there is no bubble, the aggregate value of credit limits the amount of savings through financial assets, since $\Psi_{t}=0$. In other words, the supply of asset is limited by the demand of savings. The existence of a financial bubble overcomes this limitation, since next generation purchases of the bubble, $\Psi_{t+1}$, are an additional source of demand of assets that provides liquidities in equilibrium. We can provide a graphical interpretation of (30) in terms of demand and supply of financial assets. $\Psi_{t}$ can be interpreted as the net supply of assets and it is increasing in $R_{t+1}$, as follows from (29). Following this interpretation, the net demand of financial assets is $\Psi_{t+1} / R_{t+1}$ when there is a bubble and zero otherwise. The larger demand of financial assets implies a larger return of these assets in the equilibrium with bubbles, since the supply is increasing in $R_{t+1}$. We prove this result in the following section.

An equilibrium of this economy is a path of $\left\{R_{t}, z_{t}, \tau_{t}, \bar{\delta}_{t}, \Delta_{t}\right\}_{t=1}^{\infty}$ that, given $R_{1}$ and $z_{1}$, solves the two market clearing conditions (24) and (31), satisfies (21), (23) and (29), and along which the value of the bubble is non-negative, $\Delta_{t} \geq 0 .{ }^{13}$ In the following section, we show that this equilibrium can converge to

\footnotetext{
${ }^{13}$ Note that $R_{1}=\left(\Delta_{1} / \Delta_{0}\right)\left(a_{1} / a_{0}\right)$ and $z_{1}=R_{1}\left(a_{0} / a_{1}\right)$. Since at $t=1, a_{0}, a_{1}$ and $\Delta_{0}$ are predetermined and $\Delta_{t}$ is a control variable, $R_{t}$ and $z_{t}$ are state variables.
} 
two different steady states: a bubbly steady state with $\Delta_{t}>0$ and a bubbleless one with $\Delta_{t}=0$.

\subsection{Steady states}

We denote by $g^{*}, R^{*}, \bar{\delta}^{*}$ and $z^{*}$ the constant growth factor, interest factor, ability of the marginal individual and ratio $z$ at the bubbly steady state and we denote by $g^{o}, R^{o}, \bar{\delta}^{o}$ and $z^{o}$ the corresponding values of these variables at the bubbleless steady state. In what follows, we obtain conditions that ensure existence and uniqueness of these two steady states. To this end, we rewrite the two market clearing conditions when $R_{t}=R$ and $z_{t}=z$ for all $t$ as two functions linking $z$ with $R$.

First, we consider the market clearing condition for productive capital. To this end, we first use (21) to rewrite $\tau=\widetilde{\tau}(R, \bar{\delta}, z)$ as $\tau=\tau(R, z)$. It is immediate to see that $\tau(R, z)$ is decreasing in $R$ and increasing in $z .{ }^{14}$ We use $\tau(R, z)$ to rewrite (24) as

$$
R=\frac{\gamma(1-s) A}{\chi^{1}+\phi \chi^{2}} z \tau(R, z) .
$$

Equation (32) implicitly defines an increasing and continuous function, $z=\varphi(R)$, that provides all pairs of $R$ and $z$ for which the market of productive capital clears. As follows from Assumption B, this function is defined in the domain $R \in\left(\theta s A \delta_{\max }, \omega\left(\delta_{\max }, z\right) s A \delta_{\max }\right)$. Using equation (32), we deduce that $\varphi\left(\theta s A \delta_{\max }\right)=0$ and $\varphi\left(\omega\left(\delta_{\max }, z\right) s A \delta_{\max }\right)$ diverges to infinite. ${ }^{15}$

Second, using (24) and $\pi^{2}=\chi^{2}-\eta^{2}$, we rewrite the market clearing condition for financial assets as

$$
\Delta(1-z)=0
$$

with $\Delta=\widetilde{\eta}(\bar{\delta}, z)-Q$, where

$$
\widetilde{\eta}(\bar{\delta}, z) \equiv \gamma z\left[z \widetilde{\eta}^{1}(\bar{\delta})+\phi \widetilde{\eta}^{2}(\bar{\delta})\right]+(\beta+\gamma) \chi^{1} z-\alpha \xi \phi \widetilde{\eta}^{2}(\bar{\delta})
$$

and

$$
Q=\frac{\theta s\left(\chi^{1}+\phi \chi^{2}\right)}{(1-s)}+\alpha \phi(1-\xi) \chi^{2}
$$

It will be useful to use $(21)$ to rewrite $\widetilde{\eta}(\bar{\delta}, z)$ as

$$
\eta(R, z) \equiv \gamma z\left[z \eta^{1}(R, z)+\phi \eta^{2}(R, z)\right]+(\beta+\gamma) \chi^{1} z-\alpha \xi \phi \eta^{2}(R, z) .
$$

\footnotetext{
${ }^{14}$ Remember that $\widetilde{\tau}(R, \bar{\delta}, z)$ is decreasing in both $R$ and $\bar{\delta}$ and increasing in $z$. Moreover, (21) implies that $\bar{\delta}$ is an increasing function of $R$ and a decreasing function of $z$. These relations imply that $\tau(R, z)$ is decreasing in $R$ and increasing in $z$.

${ }^{15}$ When $R$ tends to $\theta s A \delta_{\max }$, both the investment multiplier associated to $\delta_{\max }$ and $\tau\left(\theta s A \delta_{\max }, z\right)$ diverge to infinite, which implies that $\varphi\left(\theta s A \delta_{\max }\right)=0$. When $R$ tends to $\omega\left(\delta_{\max }, z\right) s A \delta_{\max }, \bar{\delta}=\delta_{\max }$, the number of entrepreneurs equals zero and $\tau\left(\omega\left(\delta_{\max }, z\right) s A \delta_{\max }, z\right)=0$, which implies that $\varphi\left(\omega\left(\delta_{\max }, z\right) s A \delta_{\max }\right)$ diverges to infinite.
} 
We proceed to show the existence of the bubbly steady state. Given that at this steady state $\Delta>0$, we deduce, from (33), that $z^{*}=1$, which implies that $R^{*}=g^{*}$. Therefore, the growth of the bubble equals the growth of wages, which is a well-known result since Tirole (1985). ${ }^{16}$ We next use the market clearing condition for productive capital to obtain that $R^{*}$ is such that $1=\varphi\left(R^{*}\right)$. Since $\varphi(R)$ is an increasing function, $\varphi\left(\theta s A \delta_{\max }\right)=0$ and $\varphi\left(\omega\left(\delta_{\max }, z\right) s A \delta_{\max }\right)$ diverges to infinite, there exists a unique $R^{*}$ that clears the market of productive capital. $R_{t}=R^{*}$ and $z_{t}=1$ define a bubbly steady state when the aggregate value of the speculative assets owned by individuals is positive; i.e. $\Delta>0$ when $R_{t}=R^{*}$ and $z_{t}=1$, which occurs when:

$$
\eta\left(R^{*}, 1\right)>Q
$$

We conclude that there exists a unique bubbly steady state when (35) is satisfied.

We next study the steady state without bubbles for which $\Delta=0$ and, hence, $\eta(R, z)=Q$. This equation implicitly defines a continuous function $z=\zeta(R)$, along which $\Delta=0$. The steady state without bubbles is the solution to equations $z=\zeta(R)$ and $z=\varphi(R)$. To show the existence of this steady state, we first define the function $z=z^{o}(\bar{\delta})$ as the solution to equation $\widetilde{\eta}(\bar{\delta}, z)=Q$. This function provides the values of $z$ and $\bar{\delta}$ for which $\Delta=0$. We use this function to define $R_{1}=s A \omega\left(\delta_{\min }, z^{o}\left(\delta_{\min }\right)\right) \delta_{\min }$ and $R_{2}=s A \omega\left(\delta_{\max }, z^{o}\left(\delta_{\max }\right)\right) \delta_{\max }$, which are, respectively, the lower and upper values of the range of $R$ that are consistent with $\lambda_{t} \in(0,1)$. Assumption $\mathrm{B}$ and $\omega_{t}>\theta$ imply that $\theta \delta_{\max } s A \in\left(R_{1}, R_{2}\right)$. Moreover, using (34) and the properties of the functions $\varphi(R)$, we obtain that $\zeta\left(R_{1}\right)>0=\varphi\left(\theta \delta_{\max } s A\right)$ and $\zeta\left(R_{2}\right)<\varphi\left(R_{2}\right)=\infty \cdot{ }^{17}$ As shown in Figure 1, these conditions imply that the functions $\zeta(R)$ and $\varphi(R)$ cross, which guarantees the existence of at least one steady state without bubbles.

While the existence of a steady state without bubbles does not depend on the shape of the function $\zeta(R)$, uniqueness depends. To determine the slope, we first assume that the function $\eta(R, z)$ increases with $z$. In the online Appendix we provide conditions that ensure that the function $\eta(R, z)$ increases with $z$. We assume that these conditions are always satisfied. In the same appendix, we show that there exist two values of $\xi$, $\xi_{1}$ and $\xi_{2}$, such that the function $\zeta(R)$ is downward slopping when $\xi \leq \xi_{1}$, upward slopping when $\xi \geq \xi_{2}$ and hump-shaped when $\xi \in\left(\xi_{1}, \xi_{2}\right)$. These three cases are shown graphically in Figure 1. The first case, shown in Panel a, corresponds to the situation in which $\xi<\xi_{1}$. Since in this case $\varphi(R)$ is increasing and $\zeta(R)$ is decreasing, there exists a unique steady state without bubbles. The second case is shown in Panel b of Figure 1 and corresponds to the situation in which $\xi>\xi_{2}$. In this case, both functions are increasing and

\footnotetext{
${ }^{16}$ If $R^{*}>g^{*}$ the bubble is not sustainable because the price grows faster than the wage and if $R^{*}<g^{*}$ the bubble asymptotically vanishes, implying that the equilibrium converges to the bubbleless steady state.

${ }^{17}$ To show that $\zeta\left(R_{1}\right)>0$ and $\zeta\left(R_{2}\right)<\infty$ it is enough to use $\eta(R, z)=Q$, where $\eta(R, z)$ is defined in $(34)$ and realize that $\eta^{j}\left(R_{1}, z\right)=0$ and $\eta^{j}\left(R_{2}, z\right)=\chi^{j}$ for all $j=1,2$.
} 
we can only guarantee the existence of at least one steady state without bubbles. Finally, Panel c shows the third case in which $\xi \in\left(\xi_{1}, \xi_{2}\right)$. In this case, the function $\zeta(R)$ is hump-shaped and we can not guarantee uniqueness of the steady state. In the online appendix, we study uniqueness and show that if $\xi$ is sufficiently small then there is a unique bubbleless steady state. ${ }^{18}$

Figure 1. Bubbly and bubbleless steady states

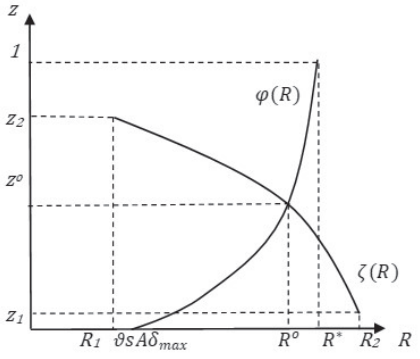

Panel a. $\xi \leq \xi_{1}$

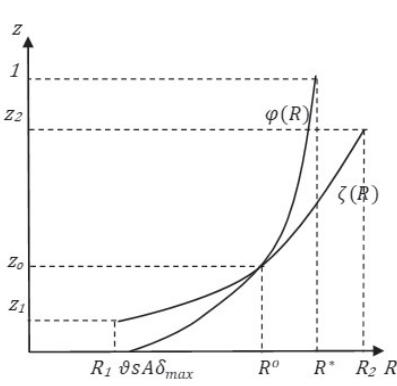

Panel b. $\xi \geq \xi_{2}$

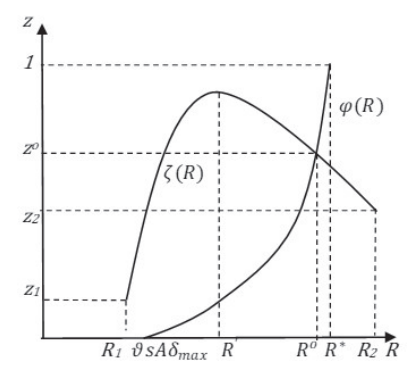

Panel c. $\xi \in\left(\xi_{1}, \xi_{2}\right)$

Finally, we compare the two steady states when we assume that there is a unique bubbleless steady state, condition (35) is satisfied and $\eta(R, z)$ increases with $z$. Condition (35) implies that the bubbly steady state satisfies $\eta\left(R^{*}, 1\right)>Q$ and remember that $\eta(R, z)=Q$ along the function $z=\zeta(R)$. Since $\eta(R, z)$ is increasing in $z$, the bubbly steady state satisfies that $1>\zeta\left(R^{*}\right)$. As it is shown in Figure 1 , this condition and $\varphi(R)$ being an increasing function imply that $R^{*}>R^{o}$ and $z^{o}<1$ when there is a unique bubbleless steady state. ${ }^{19}$ The first inequality implies that the return of financial assets is larger in the bubbly steady state. This is a well-known result that is explained because the bubble increases the savings devoted to the demand of financial assets (see, for instance, Fahri and Tirole, 2012). The second inequality implies that $R^{o}<g^{o}$, which is also a well-known relation that the bubbleless steady state must satisfy to ensure the

\footnotetext{
${ }^{18}$ More precisely, we show that if $\xi$ is small then the function $\zeta(R)$ is flatter than $\varphi(R)$ in the whole domain $R \in\left(R_{1}, R_{2}\right)$, which guarantees uniqueness of the bubbleless steady state.

${ }^{19}$ Since $\eta(R, z)$ is increasing in $z$, the value of financial assets is negative below the function $\zeta(R)$ and positive above. This explains that the bubbly steady state is above this function.
} 
existence of a bubbly steady state (see Grossman and Yanagawa, 1993). Therefore, we have shown that some classical results that the literature has obtained in models in which individuals of the same generation are identical remain when we consider heterogeneous individuals. The following proposition summarizes the results obtained in this section.

Proposition 1 If Assumptions $A$ and $B$ and condition (35) are satisfied then:

(i) There exists a unique bubbly steady state that satisfies $R^{*}=g^{*}$.

(ii) There exists a unique bubbleless steady state when $\xi$ is sufficiently small. This steady state satisfies $R^{o}<g^{o}$ and $R^{*}>R^{o}$.

Proof. The existence of steady states follows from the previous arguments and uniqueness of the bubbleless steady state when $\xi$ is sufficiently small is shown in the online appendix.

In the online appendix, we also study stability and we show that when $\theta=0$ and $\xi$ is sufficiently small then the bubbleless steady state is locally stable and the bubbly steady state is either locally stable or saddle path stable. These results are obtained for restrictive parameter conditions. However, using several numerical examples, we show that local stability of the bubbleless steady state and saddle path stability of the bubbly steady state seem a robust finding. These results imply that the equilibrium can convergence to both steady states and, therefore, the particular steady state to which the equilibrium converges depends on individuals expectations.

\section{Entrepreneurs, growth and productivity}

In this section, we study the effect of the bubble on the number and the size of entrepreneurs, economic growth and TFP. We first study the composition effect of the bubble, which is the effect of the bubble on the composition of the population between entrepreneurs and savers and it is determined by the ability of the marginal individual, $\bar{\delta}_{t}$. As follows from (21), this ability increases with $R_{t+1}$ and decreases with the ratio $z_{t}$. Since the bubble increases both $R_{t+1}$ and $z_{t}$, the effect of the bubble on the number of entrepreneurs is ambiguous. This ambiguity is the consequence of two opposite mechanisms. On the one hand, in a bubbly economy the return on financial assets is larger, which implies that more individuals choose to be savers. On the other hand, adult individuals are wealthier with the bubble. As a result, more individuals find affordable the start-up cost. Therefore, the number of entrepreneurs is larger in the bubbly economy when this cost mechanism dominates, which occurs when the start-up cost rate is sufficiently large.

In this last case, the bubble increases the number of entrepreneurs by reducing the ability of the marginal individual. This implies that new entrepreneurs are less productive than existing ones. Moreover, these new 
entrepreneurs benefit from a smaller investment multiplier and a lower labor income and, hence, they invest less. Therefore, new entrepreneurs are less productive and own smaller firms, which are two features observed in firm-level data.

We next analyze the effect of the bubble on growth. To this end, we use (24) to obtain

$$
g_{t+1}=\frac{A \gamma(1-s)}{\chi^{1}+\phi \chi^{2}} \widetilde{\tau}\left(\bar{\delta}_{t}, z_{t}, R_{t+1}\right) .
$$

Equation (36) shows that the bubble may only increase growth if it enlarges $\tau_{t}$, which depends on three variables that introduce three distinct effects of the bubble. The first variable, $\bar{\delta}_{t}$, measures the composition effect of the bubble. A larger $\bar{\delta}_{t}$ reduces the number of entrepreneurs and, as a consequence, capital accumulation and growth decrease. Since the bubble may either increase or decrease the number of entrepreneurs, the composition effect of the bubble on growth is ambiguous. It is positive when the start-up cost rate is large, since the number of entrepreneurs increases in this case. This result is consistent with findings in the literature on entrepreneurship showing that more entrepreneurs increase growth (see Quadrini, 2009).

The second variable, $z_{t}$, measures the liquidity effect of the bubble, which has been introduced in other papers (Martin and Ventura, 2012 or Fahri and Tirole, 2012). Since part of the labor income is obtained in the first period of life but investment can only be done in the second, the bubble provides liquidities that increase the present value labor income in the second period of life. As a consequence, adult individuals are wealthier, which increases capital accumulation and growth.

To gain some additional intuition on the liquidity effect, we assume that $\theta=0$. In this case, adult individuals save, as the aggregate financial assets of adult savers and entrepreneurs satisfy $x_{2, t}^{S}>0$ and $x_{2, t}^{E}=0$. Since in the bubbleless economy the value of the aggregate financial assets equals zero, the aggregate financial assets of young individuals must be negative, i.e. $x_{1, t}^{S}+x_{1, t}^{E}<0$. In other words, young individuals borrow from the deposits accumulated by adult savers. These loans are paid back when adult, which limits productive investment. In contrast, in the bubbly economy, aggregate financial assets are positive. That is, young individuals can hold the bubble and sell it in the following period, even if adult individuals also buy the bubble to postpone consumption. As a consequence, the amount borrowed when young and the amount adult individuals must pay for the credit decline with the bubble. Adult individuals then are wealthier and can invest more in productive capital. In this way, the bubble provides liquidities to adult credit constrained entrepreneurs. The same intuition applies when $\theta>0$ but not too large.

We have seen that the liquidity effect implies that the bubble makes adult individuals wealthier. As a result, entrepreneurs increase investment and more individuals find affordable the start-up cost and become entrepreneurs. Thus, the aforementioned cost mechanism of the bubble can be interpreted as the extensive margin of the liquidity effect. Following this interpretation, the increase in investment of each entrepreneur 
corresponds to the intensive margin.

The last variable, $R_{t+1}$, measures the leverage effect of the bubble that has also been considered by other papers in the literature (Fahri and Tirole, 2012). By increasing $R_{t+1}$, the bubble reduces the amount of credit that can be obtained using productive investment as collateral. As a result, the investment multiplier of each entrepreneur decreases, which reduces aggregate investment and growth. From the expression of the investment multiplier, it is immediate to see that the leverage effect of the bubble on growth weakens when the degree of pledgeability, measured by $\theta$, is smaller and disappears when $\theta=0 .{ }^{20}$

We conclude that it is more likely that the bubble increases growth when the degree of pledgeability is small and the start-up cost rate is large.

Finally, we consider the effect of the bubble on TFP. In Section 2.1, we have introduced an aggregate production function that satisfies $y_{t}=A k_{t}$. However, TFP is endogenous, since entrepreneurs have heterogeneous productivities to transform investment into capital. To obtain TFP, recall that each entrepreneur produces with the same technology $y_{t+1}^{i}=F\left(\delta^{i} \kappa_{t+1}^{i}, \bar{a}_{t} l^{i}\right)$, where $y_{t+1}^{i}$ is the output produced by entrepreneur $i$. Since the technology exhibits constant returns to scale and the labor market is competitive, we have $\delta^{i} \kappa_{t+1}^{i}=\bar{a}_{t} l^{i}$ for all entrepreneurs at the equilibrium and the production function can be rewritten as follows $y_{t+1}^{i}=A \delta^{i} \kappa_{t+1}^{i} \cdot{ }^{21}$ The aggregate production is $y_{t+1}=\int \delta_{\delta_{t}}{ }_{\max } y_{t+1}^{i} f\left(\delta^{i}\right) d \delta^{i}$ and it is immediate to see that $y_{t+1}=p_{t} \int_{\bar{\delta}_{t}}^{\delta_{\max }} \kappa_{t+1}^{i} f\left(\delta^{i}\right) d \delta^{i}$, where

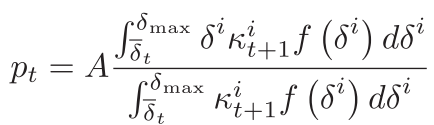

is TFP, which is equal to the average return that entrepreneurs obtain per unit invested.

Since the productivity of each entrepreneur is constant, TFP depends only on two margins: extensive, related to the number of entrepreneurs, and intensive, which is determined by the amounts invested by each entrepreneur. First, since new entrepreneurs are less productive, any increase in the number of entrepreneurs reduces TFP. Second, the intensive margin, introduced by Miao and Wang (2012), increases TFP when the amount invested by more productive entrepreneurs increases relative to the amount invested by less productive entrepreneurs. In what follows, we show how these two margins are affected by the bubble in this model. To this end, we use (3), (18), and (23) to rewrite TFP as

$$
p_{t}\left(\bar{\delta}_{t}, R_{t+1}, z_{t}\right)=A \tau_{t}\left(\bar{\delta}_{t}, R_{t+1}, z_{t}\right) / \nu_{t}\left(\bar{\delta}_{t}, R_{t+1}, z_{t}\right),
$$

\footnotetext{
${ }^{20}$ These results, related to the degree of pledgeability, are in line with those obtained in Clain-Chamosset-Yvrad, et al. (2020). In this paper, we consider a model in which individuals of the same generation are identical and study how the growth effects of the bubble depend on the degree of pledgeability. We show that growth is larger with the bubble when the degree of pledgeability is sufficiently small.

${ }^{21} \mathrm{~A}$ competitive labor market implies that the wage per efficiency unit equals the marginal productivity of one efficiency unit and is the same for all workers.
} 
where

$$
\nu_{t}=\int_{\bar{\delta}_{t}}^{\delta_{\max }} \frac{1}{1-\theta q_{t+1}^{i} / R_{t+1}}\left[z_{t}\left(\delta^{i}\right)^{v_{1}} d \delta^{i}+(1-\xi) \phi\left(\delta^{i}\right)^{v_{2}}\right] f\left(\delta^{i}\right) d \delta^{i} .
$$

TFP depends on the same three variables, $\bar{\delta}_{t}, R_{t+1}$ and $z_{t}$, which measure the composition, leverage and liquidity effects of the bubble. The composition effect directly alters the extensive margin. An increase in $\bar{\delta}_{t}$ reduces the number of entrepreneurs and, since the remaining ones are more productive, TFP increases. Following the same argument, we assert that the composition effect reduces TFP when the bubble increases the number of entrepreneurs.

The leverage and liquidity effects of the bubble affect TFP through the intensive margin. First, the leverage effect of the bubble is the consequence of the reduction in the investment multiplier due to the increase in the returns of financial assets. This effect is larger for more productive entrepreneurs, as follows immediately from the expression of the multiplier. This implies that the leverage effect reduces to a larger extend the investment of more productive entrepreneurs and, hence, it reduces TFP.

Second, the liquidity effect, measured by the variable $z_{t}$, also affects TFP through the intensive margin. In Appendix B, we show that the liquidity effect increases TFP only when $v_{1}>v_{2}$. In this case, the distribution of wages of the young individuals is more correlated with investment productivity than the distribution of wages of the adult. To understand how the liquidity effect affects TFP, remember that the ratio $z_{t}$ determines the effect that the wages of the young individuals have on the wealth of adult individuals. Indeed, the bubble provides liquidities because young individuals obtain wages one period before individuals invest. Therefore, the liquidity effect of the bubble causes a larger increase in investment when the wages of the young individuals are larger. As a result, when the wages of the young individuals are more correlated with the productivity of investment, the liquidity effect is more intense for more productive entrepreneurs. In this case, the bubble increases to a larger extend the investment of these more productive entrepreneurs. This explains that the liquidity effect increases TFP when the productivity of investment is more correlated with the wages of the young than with the wages of the adult. Finally, note that since the leverage and composition effects reduce TFP when the number of entrepreneurs increases with the bubble, TFP can only be larger with the bubble if the liquidity effect increases TFP, which requires $v_{1}>v_{2}$.

To summarize, we show that when the start-up cost rate is large, the degree of pledgeability is small and the productivity of investment is more correlated with the wages of the young than with the wages of the adult, the bubble increases the number of entrepreneurs and growth and may increase productivity. Moreover, we also show that the individuals that are entrepreneurs only when there is a bubble are less productive and invest less than the rest of entrepreneurs. We conclude that this model explains the different facts mentioned in the introduction. 


\subsection{Numerical examples}

We use numerical examples to show that our model can explain the empirical facts. In these examples, we assume that abilities follow a Pareto truncated distribution with density function:

$$
f(\delta)=\frac{\psi \delta_{\min }^{\psi}}{1-\left(\delta_{\min } / \delta_{\max }\right)^{\psi}} \delta^{-(1+\psi)},
$$

where the parameter $\psi>0$ determines the shape of the density function.

\section{Table 1}

\begin{tabular}{|c|c|c|c|c|}
\hline Parameters & Values & Targets & Data & Model \\
\hline$A$ & 10 & Normalization & - & - \\
\hline$s$ & 0.4 & Labor Income Share $^{a}$ & $60 \%$ & $60 \%$ \\
\hline$\alpha$ & 0.422 & Consumption to I. ratio of the young ${ }^{b}$ & $84 \%$ & $84 \%$ \\
\hline$\beta$ & 0.411 & Consumption to I. ratio of the adult ${ }^{b}$ & $85 \%$ & $85 \%$ \\
\hline$\gamma$ & 0.167 & Normalization & -- & -- \\
\hline$\delta_{\min }$ & 1 & Normalization & - & -- \\
\hline$\delta_{\max }$ & 16 & Annual growth rate in the bubbly S.S. & -- & $2.67 \%$ \\
\hline$\psi$ & 1.214 & Fraction of entrepreneurs in labor force ${ }^{c}$ & $10.6 \%$ & $10.8 \%$ \\
\hline$\phi$ & 2.2 & Adult to young labor Income. ${ }^{b}$ & 1.12 & 1.15 \\
\hline$v_{2}$ & 0.4 & Third to first labor income quartile ${ }^{b}$ & 1.97 & 1.52 \\
\hline$\xi$ & 0.75 & Start-up cost to GDP & -- & $17.45 \%$ \\
\hline$v_{1}$ & 1 & Assumption & -- & \\
\hline$\theta$ & 0 & Assumption & - & \\
\hline
\end{tabular}

The parameters in the benchmark economy are set to match several targets of the US economy in the period 2010-2020. First, technological parameters, $s$ and $A$, are set so that the labor income share equals $60 \%$. Second, preference parameters, $\alpha, \beta$ and $\gamma$, are set so that the ratio of consumption expenditure to income equals $84 \%$ in the first period of life and to $85 \%$ in the second period of life. ${ }^{22}$ Third, the parameters of the density function, $\delta_{\min }, \delta_{\max }$ and $\psi$, are set to have in the bubbly steady state an annual growth rate

\footnotetext{
${ }^{22}$ We obtain the consumption expenditure to income ratio from the 2019 US consumption expenditure survey. We obtain the value of this ratio in the first period of life as the average value of the ratio between annual expenditures and after tax income for households whose reference person is aged between 25 and 44 years and the value of this ratio in the second period is also the average value of the ratio between annual expenditures and after tax income for households whose reference person is aged between 45 and 64 .
} 
close to $2.5 \%$ and a fraction of the entrepreneurs in the labor force of $10.6 \%{ }^{23}$ Forth, the labor earnings parameters $\phi$ and $v_{2}$ are set so that the labor income in the second period of life is $12 \%$ larger than in the first period and to match that the average labor income of the third quartile is $97 \%$ larger than the average labor income of the first quartile. ${ }^{24}$ Finally, the rest of parameters of the benchmark economy are set so that the equilibrium of this economy is consistent with the facts explained in the introduction, which requires a low pledgeability of capital, a larger correlation between the return of investment and wages of the young than of the adult individuals and a large start-up cost rate. In particular, we assume that productive capital cannot be used as collateral, $\theta=0$, that $v_{1}=1$ and, hence, $v_{1}>v_{2}$, and we set $\xi=0.75$, which implies that the start-up cost is $17.45 \%$ of the GDP per capita. ${ }^{25}$ Table 1 summarizes the parameters of the calibration.

Table 2 shows the values of the return of financial assets, growth rate, fraction of entrepreneurs and productivity in the bubbly and in the bubbleless steady states. From the comparison between the two steady states of the benchmark economy, it follows that growth and the return of financial assets are clearly larger with bubbles and both the number of entrepreneurs and TFP are slightly larger in the bubbly steady state. Thus, in the benchmark economy, bubbles increase the number of entrepreneurs, growth and TFP and, hence, this economy is consistent with the empirical findings mentioned in the introduction. At this point, some words of caution are appropriate, since the effect of the bubble on the number of entrepreneurs and on TFP is too small to explain the fluctuations observed in these two variables as a result of the transition between the two steady states. Basu et al. (2006) and Tian (2018) report fluctuations of TFP of around $5 \%$ and in the number of entrepreneurs around $2 \%$. Our tractable model does not generate these variations. However, in the online appendix we show numerically that a more complex version of the model in which the return of investment is a convex function rather than a linear function of abilities accounts for these fluctuations. ${ }^{26}$ More precisely, we consider that $q_{t}^{i}=q_{t} \delta^{1.1}$, we calibrate the economy and show that the bubble increases growth by $71 \%$, the number of entrepreneurs by $2 \%$ and TFP by $5 \%$.

\footnotetext{
${ }^{23}$ The fraction of entrepreneurs is obtained from the OECD as the ratio between self-employed (both own-account workers and also self-employed who are employers) and total employment. This ratio changes substantially among OECD countries. In the US, this ratio is $10.6 \%$.

${ }^{24}$ Data on the distribution of labor income across age groups and income quartiles is obtained from the US Bureau of Labor Statistics, first quartile of 2020. The income of the age groups is defined as the median income of individuals aged between 25 and 44 for the first period of life and between 45 and 64 for the second period.

${ }^{25}$ Start-up cost is measured as a bureaucratic cost by Klapper et al. (2006). They report huge differences across countries. The cost ranges between $0.5 \%$ and $81 \%$ of per capita GNP.

${ }^{26}$ When the return of investment is a convex function of abilities, the model is complex and we only solve it numerically.
} 
Table 2

\begin{tabular}{|c|c|c|c|c|}
\hline Bubbly & Benchmark & Economy 1 & Economy 2 & Economy 3 \\
\hline$R=g$ & 1.70 & 2.30 & 1.20 & 0.44 \\
\hline$\lambda$ & 0.108 & 0.198 & 0.063 & 0.041 \\
\hline$p$ & 92.3 & 75.8 & 107 & 115 \\
\hline Value bubble & 1.11 & 1.01 & 1.16 & 0.27 \\
\hline \multicolumn{5}{|l|}{ Bubbleless } \\
\hline$R$ & 0.53 & 0.87 & 0.30 & 0.32 \\
\hline$g$ & 0.99 & 1.62 & 0.56 & 0.38 \\
\hline$\lambda$ & 0.107 & 0.267 & 0.047 & 0.039 \\
\hline$p$ & 91.9 & 67.1 & 114 & 117 \\
\hline
\end{tabular}

Eco. 1: $\xi=0.5$; Eco. 2: $\xi=1$; Eco. $3: v_{1}=v_{2}=0.4$.

The results for the benchmark economy show that the composition effect of the bubble is small, since the differences in the number of entrepreneurs between the two steady states are quite small. However, this conclusion changes when we consider other economies with a different start-up cost rate. To show this, we compare the benchmark economy with three different counterfactual economies. First, Economy 1 differs from the benchmark economy in the value of the start-up cost rate, which is substantially smaller. As a result, compared to the benchmark economy, there are more entrepreneurs at both steady states. This larger amount of entrepreneurs explains the larger growth and the smaller TFP in both steady states. Moreover, the reduction in the start-up cost rate weakens the cost mechanism, which explains that in Economy 1 there are more entrepreneurs in the bubbleless economy than in the bubbly one. As a consequence, the composition effect of the bubble reduces the differences between the growth rates of the bubbly and the bubbleless steady state, whereas it increases substantially the differences in TFP. In this economy, the composition effect is sizable as a result of the large differences in the number of entrepreneurs between the two steady states.

In Economy 2, the start-up cost rate is larger than in the benchmark economy. This larger cost rate explains the smaller fraction of entrepreneurs, which reduces growth and increases TFP in both steady states. In this economy, the cost mechanism is more intense than in the benchmark and, as a consequence, the fraction of entrepreneurs is substantially larger in the bubbly steady state than in the bubbleless one. This implies that the composition effect of the bubble is large, which explains that TFP is smaller in the bubbly steady state. 
Finally, in Economy 3, the correlation between productivity of investment and wages is equal at both periods of life. As a consequence, the liquidity effect of the bubble does not affect TFP. Since the number of entrepreneurs is larger in the bubbly steady state, the TFP is smaller in the bubbly steady state due to the composition effect.

These numerical examples suggest that the composition effect may be sizeable and determine the overall effect that bubbles have on growth and productivity. More specifically, Economies 1 and 2 show that the startup cost rate crucially determines the direction and intensity of the composition effect. Klapper, et al. (2006) show that this cost rate varies substantially across countries. This suggests that cross-country differences on the effect that bubbles have on growth and productivity could be explained by differences in this cost rate. These cross-country differences could also be explained by differences in the wage distribution. More precisely, in Economy 3, we show that the correlation between wages and the return of productive investment is another determinant of the effect of bubbles on productivity. Therefore, cross-country differences in these correlations could be an alternative explanation of differences in the effect of bubbles.

\subsection{Comparison with the literature}

To organize the comparison between our paper and the literature that studies the effects of financial bubbles in models with heterogeneous individuals, we distinguish three groups of models: (i) models with two exogenous groups of individuals: savers and entrepreneurs; (ii) with two exogenous groups of entrepreneurs: high and low ability entrepreneurs; and (iii) with endogenous composition of the population between savers and entrepreneurs.

\section{(i) Savers and entrepreneurs}

Martin and Ventura (2012), Fahri and Tirole (2012) and Raurich and Seegmuller (2019) among many others have considered models in which the population is divided in two constant groups of individuals. The model of Section 2 can be adapted to this setting by assuming that the distribution function of $\delta$ is discrete and has the following properties: a constant fraction $\lambda$ of individuals has a high ability, $\delta^{H}$, and the rest, $1-\lambda$, has low ability, $\delta^{L}$. Moreover, we assume that the support of the distribution satisfies $\delta^{L}<R_{t+2} /(\omega s A)<\delta^{H}$. This assumption implies that in equilibrium individuals with low ability will be savers and individuals with high ability will be entrepreneurs. Therefore, the fraction of entrepreneurs in the population is constant, it is equal to the parameter $\lambda$, and it is not affected by the bubble. In other words, the bubble does not cause the composition effect.

In this setting, using (37), we obtain that $p=A \delta^{H}$. Therefore, TFP is constant and it is not affected by the bubble. Moreover, using (36), we obtain that the ratio between the growth rate in the bubble and in the 
bubbleless steady states equals

$$
\frac{g^{*}}{g^{o}}=\left(\frac{\left(\delta^{H}\right)^{v_{1}-v_{2}}+\phi(1-\xi)}{z^{o}\left(\delta^{H}\right)^{v_{1}-v_{2}}+\phi(1-\xi)}\right)\left(\frac{1-\theta \delta^{H} s A / R^{o}}{1-\theta \delta^{H} s A / R^{*}}\right)
$$

The ratio of growth rates is equal to the product of two ratios. The first one measures the liquidity effect of the bubble and it is larger than one because $z^{o}<1$. This effect is reinforced by a high value of $\left(\delta^{H}\right)^{v_{1}-v_{2}}$. The second one measures the leverage effect of the bubble and it is smaller than one since $R^{*}>R^{o}$. Therefore, in models that divide the population into two constant and homogeneous groups of individuals, the bubble increases growth when the liquidity effect dominates the leverage effect. However, these models do not explain that productivity and entrepreneurship increase with the bubble.

\section{(ii) High and low ability entrepreneurs}

Miao and Wang (2012) and Hirano and Yanagawa (2017) consider two constant groups of entrepreneurs with different ability to account for the effects that the bubble may have on TFP through the intensive margin. The model of Section 2 can also be adapted to this context. To this end, we assume again that the distribution function of $\delta$ is discrete and has the following properties: a constant fraction $\lambda^{L}$ of individuals has low ability, $\delta^{L}$, a constant fraction $\lambda^{M}$ has a middle ability, $\delta^{M}$, and the rest, $\lambda^{H}$, has high ability, $\delta^{H}$. Obviously, $\lambda^{L}+\lambda^{M}+\lambda^{H}=1$. We also assume that $\delta^{L}<R_{t+2} /(\omega s A)<\delta^{M}$, which implies that low ability individuals are savers and the rest, middle and high ability individuals, are entrepreneurs.

As occurs in models with identical entrepreneurs, the fraction of entrepreneurs in the population is constant, equal to $\lambda^{M}+\lambda^{H}$, and it is not affected by the bubble. The bubble also increases growth when the liquidity effect dominates the leverage effect of the bubble. However, since there are two different groups of entrepreneurs, the bubble affects TFP through the intensive margin. To see this, we use (37) to obtain that TFP equals

$$
p_{t}=A \frac{\delta^{M} \frac{z_{t}\left(\delta^{M}\right)^{v_{1}}+(1-\xi) \phi\left(\delta^{M}\right)^{v_{2}}}{1-\theta \delta^{M} s A / R_{t+1}} \lambda^{M}+\delta^{H} \frac{z_{t}\left(\delta^{H}\right)^{v_{1}}+(1-\xi) \phi\left(\delta^{H}\right)^{v_{2}}}{1-\theta \delta^{H} s A / R_{t+1}} \lambda^{H}}{\frac{z_{t}\left(\delta^{M}\right)^{v_{1}}+(1-\xi) \phi\left(\delta^{M}\right)^{v_{2}}}{1-\theta \delta^{M} s A / R_{t+1}} \lambda^{M}+\frac{z_{t}\left(\delta^{H}\right)^{v_{1}}+(1-\xi) \phi\left(\delta^{H}\right)^{v_{2}}}{1-\theta \delta^{H} s A / R_{t+1}} \lambda^{H}} .
$$

It is immediate to see that TFP decreases with $R_{t+1}$ and increases with $z_{t}$ if and only if $v_{1}>v_{2}$. Since the bubble increases $R_{t+1}$ and $z_{t}$, the bubble affects TFP through the leverage and liquidity effects.

Models with two groups of entrepreneurs can explain that growth and productivity are larger with bubbles. However, they do not consider the composition effect of the bubble, which may be sizeable according to our numerical examples. 
(iii) Endogenous composition of the population

Kunieda and Shibata (2016) consider a model with a continuous distribution function of abilities to study the effect of the bubble on growth when the composition of the population between savers and entrepreneurs is endogenous. Our model of Section 2 particularizes to their setting when $\theta=\xi=0$ and $v_{j}=0, j=1,2$.

A first difference with our paper is that they do not introduce the start-up cost. As a consequence, the number of entrepreneurs is smaller in the bubbly steady state. A second difference is that productive capital is not used as collateral and, hence, the bubble does not cause the leverage effect. Therefore, as follows from (23) and (36), the bubble causes two opposite effects on growth. First, the smaller number of entrepreneurs reduces capital accumulation and growth. This is the composition effect of the bubble. Second, the bubble still has a growth enhancing liquidity effect. Thus, the bubble promotes growth when the reduction in the number of entrepreneurs is not too large. Finally, TFP simplifies as follows

$$
p_{t}\left(\bar{\delta}_{t}\right)=A \frac{\int_{\bar{\delta}_{t}}^{\delta_{\max }} \delta^{i} f\left(\delta^{i}\right) d \delta^{i}}{\int_{\bar{\delta}_{t}}^{\delta_{\max }} f\left(\delta^{i}\right) d \delta^{i}} .
$$

Since $v_{j}=0$, the liquidity effect of the bubble does not alter TFP. Therefore, TFP only depends on the composition effect. Given that in this economy the bubble reduces the number of entrepreneurs, TFP increases.

\section{Concluding remarks}

Asset prices, TFP and entrepreneurship are procyclical, whereas new firms that enter in booms are less productive and smaller. We explain these facts by interpreting asset price fluctuations as the result of a transition between two steady states: a steady state without bubbles, in which financial assets consists only of deposits, and another one with bubbles, in which financial assets also include a pure speculative asset.

We show that the aforementioned facts can be explained in an overlapping generations growth model populated by heterogenous individuals that live for three periods. We distinguish three dimensions of heterogeneity. First, individuals are heterogeneous in the return of productive investment. This heterogeneity separates individuals in two groups: savers and entrepreneurs. Savers only invest in financial assets, whereas entrepreneurs borrow from the savers to invest in productive capital. A novelty of this paper is the introduction of a start-up cost that entrepreneurs must pay. The bubble changes the composition of the population between savers and entrepreneurs. On the one hand, the bubble increases the return of financial assets, which increases the amount of savers. On the other hand, the bubble reduces the start-up cost as a fraction of labor income. As a result, more individuals are willing to pay the cost and become entrepreneurs. We show that the bubble increases the number of entrepreneurs when this cost mechanism dominates. 
Second, workers are heterogeneous since individuals work both when young and adult. Since investment can only be done when adult and part of the labor income is obtained when young, the bubble provides liquidities to credit constrained entrepreneurs. This is the liquidity effect of the bubble that increases growth. However, the bubble also increases the return of financial assets, which causes a negative growth effect when productive capital is used as collateral. This is the leverage effect of the bubble. The bubble also increases growth by increasing the number of entrepreneurs. This is the composition effect of the bubble, which is a major contribution of this paper.

Third, wages are heterogenous among workers of the same generations, which is another novelty of this paper. We show that this dimension of heterogeneity is necessary to explain that TFP is larger with bubbles. In particular, we show that the liquidity effect of the bubble increases TFP when the productivity of investment is more correlated with the wages of the young than with the wages of the adult. In this case, the bubble further increases the investment of more productive entrepreneurs, which causes the increase in TFP.

We conclude that the model explains the aforementioned facts when we introduce two crucial assumptions: a large start-up cost rate and a larger correlation between the productivity of investment and the wages of the young than with the wages of the adult. The first assumption is needed to explain that entrepreneurship is larger with the bubble. The second assumption is needed to explain a larger TFP with the bubble. This assumption is aimed to ensure that more productive entrepreneurs obtain a larger income in the first period. Therefore, this second assumption could be generalized by assuming that the return of productive investment is correlated with income when young, which in addition to labor income could also include transfers, bequests or profits. This suggests that similar results could be obtained in different settings. For instance, we conjecture that our results could be obtained in models in which individuals decide in the first period between being workers and entrepreneurs. Individuals that decide to be entrepreneurs when young would also be entrepreneurs when adult. Since more productive entrepreneurs obtain larger income (profits) when young, these more productive entrepreneurs would benefit more when adult of the liquidities provided by the bubble. As a result, the bubble would further increase investment of more productive entrepreneurs. This would provide an alternative explanation of the positive effects of bubbles on TFP. 


\section{References}

[1] Aghion, P., Bergeaud, A., Cette, G., Lecat, R. and Maghin H. (2019). Coase lecture - The Inverted-U relationship between credit access and productivity growth. Economica, 86, 1-31.

[2] Basu, S. and Fernald, J. (2001). Why is productivity procyclical? Why do we care?, in New Development in Productivity Analysis, eds. Charles R. Hulten, Edwin R. Dean, and Michael J. Harper, 224-296. NBER. Available at http://www.nber.org/chapters/c10128.

[3] Basu, S., Fernald, J. and Kimball, M. (2006). Are technology improvements contractionary?, American Economic Review, 96 (5), 1418-1448.

[4] Bartelsman, E. and Doms, M. (2000). Understanding productivity: Lessons from longitudinal microdata. Journal of Economic Literature, 38 (3), 569-594.

[5] Basco, S. (2016). Switching bubbles: From outside to inside bubbles. European Economic Review, 87, 236-255.

[6] Bengui, J. and Phan, T. (2018). Asset pledgeability and endogenously leveraged bubbles. Journal of Economic Theory, 177, 280-314.

[7] Bilbiie, F., Ghironi, F. and Melitz, M. (2012). Endogenous entry, product variety, and business cycles. Journal of Political Economy, 120 (2), 304-345.

[8] Buera, F.J., Kaboski, J. P. and Shin, Y. (2011). Finance and development: A tale of two sectors. American Economic Review, 101, 1964-2002.

[9] Caballero, R. J., Fahri, E. and Hammour, M. L. (2006). Speculative growth: hints from the U.S. economy. American Economic Review 96, 1159-1192.

[10] Campbell, J. (1998). Entry, exit, embodied technology, and business cycles. Review of Economic Dynamics, 1, 371-408.

[11] Campbell, J. (1999). Asset prices, consumption, and the business cycle. Handbook of Macroeconomics, Volume 1, Part C, Chapter 19, 1231-1303.

[12] Chatterjee, S., Cooper, R. and Ravikumar, B. (1993). Strategic complementarity in business formation: aggregate fluctuations and sunspot equilibria, Review of Economic Studies, 60, 795-811.

[13] Clain-Chamosset-Yvrad, L. Raurich, X. and Seegmuller, T. (2020). Are the liquidity and collateral roles of asset bubbles different?, halshs-02536396. 
[14] Clementi, G. and Palazzo, B. (2016). Entry, exit, firm dynamics, and aggregate fluctuations. American Economic Journal: Macroeconomics, 8 (3), 1-41.

[15] Cooley, T.F. and Quadrini, V. (2001). Financial markets and firm dynamics. American Economic Review, 91, 1286-1310.

[16] Fagereng, A., Guisso, L., Malacrino, D. and Pistaferri, L. (2020). Heterogeneity and persistence in returns to wealth. Econometrica, 88 (1), 115-170.

[17] Farhi, E. and Tirole, J. (2012). Bubbly liquidity. Review of Economic Studies, 79, 678-706.

[18] Fernald, J. and Wang, C. (2016). Why has the cyclicality of productivity changed? What does it mean? Annual Review of Economics, 8, 465-496.

[19] Field, A. (2010). The procyclical behavior of total factor productivity in the United States, 1890-2004. The Journal of Economic History, 70 (2), 326-350.

[20] Graczyk, A. and Phan, T. (2018). Regressive welfare effects of housing bubbles. Working Paper 18-10, Federal Reserve Bank of Richmond.

[21] Grossman, G. and Yanagawa, N. (1993). Asset bubbles and endogenous growth. Journal of Monetary Economics, 31, 3-19.

[22] Hillebrand, M., Kikuchi, T. and Sakuragawa, M. (2018). Bubbles and crowding-in of capital via a savings glut. Macroeconomic Dynamics, 22 (5), 1238-1266.

[23] Hirano, T. and N. Yanagawa (2017). Asset bubbles, endogenous growth, and financial frictions. The Review of Economic Studies, 84, 406-443.

[24] Jeong, H. and Townsend, R.M. (2007). Sources of TFP growth: occupational choice and financial deepening. Economic Theory, 32, 179-221.

[25] Klapper, L., Laeven, L. and Rajan, R. (2006). Entry regulation as a barrier to entrepreneurship. Journal of Financial Economics, 82, 591-629.

[26] Klapper, L., and Love, I. (2011). The impact of financial crisis in new firm registration, Economics Letters, 113, 1-4.

[27] Kocherlakota, N. (2009). Bursting bubbles: consequences and cures, mimeo, Federal Reserve Bank of Minneapolis. 
[28] Koellinger, P. and Thurik, R. (2012). Entrepreneurship and the business cycle. The Review of Economics and Statistics, 94 (4), 1143-1156.

[29] Kunieda, T. (2008). Asset bubbles and borrowing constraints. Journal of Mathematical Economics, 44, 112-131.

[30] Kunieda, T. (2014). A note on the crowd-in effect of asset bubbles in the perpetual youth model. Mathematical Social Sciences, 72, 50-54.

[31] Kunieda, T. and Shibata, A. (2016). Asset bubbles, economic growth, and a self-fulfilling financial crisis. Journal of Monetary Economics, 82, 70-84.

[32] Lee, Y. and Mukoyama, T. (2015). Entry and exit of manufacturing plants over the business cycle. European Economic Review, 77, 20-27.

[33] Martin, A. and Ventura, J. (2012). Economic growth with bubbles. American Economic Review, 102, 3033-58.

[34] Martin, A. and Ventura, J. (2016). Managing credit bubbles. Journal of the European Economic Association, 14, 753-789.

[35] Meza, F. and Quintin, E. (2005). Financial crises and total factor productivity. Center for Latin America Working Papers, Federal Reserve Bank of Dallas no. 105.

[36] Miao, J. and Wang P. (2012). Bubbles and total factor productivity. American Economic Review: Papers E Proceedings, 2012, 102(3), 82-87.

[37] Midrigan, V. and Xu, D. Y. (2014). Finance and misallocation: evidence from plant-level data. American Economic Review, 104, 422-458.

[38] Moll, B. (2014). Productivity losses from financial frictions: can self-financing undo capital misallocation?. American Economic Review, 104, 3186-3221.

[39] Poschke, M. (2013). Who becomes an entrepreneur? Labor market prospects and occupational choice. Journal of Economics Dynamics and Control, 37, 693-710.

[40] Pratap, S. and Urrutia, C. 2012. Financial frictions and total factor productivity: accounting for the real effects of financial crises. Review of Economic Dynamics, 15(3), 336-358.

[41] Queralto, A. (2011). Financial market frictions, productivity growth and crises in emerging economies. Meeting Papers 697, Society for Economic Dynamics. 
[42] Quadrini, V. (2009). Entrepreneurship in macroeconomics. Annals of Finance, 5, 295-311.

[43] Raurich, X. and Seegmuller, T. (2019). On the interplay between speculative bubbles and productive investment. European Economic Review, 111, 400-420.

[44] Tang, H. (2018). Asset price bubbles and the distribution of firms. Meeting Papers 362, Society for Economic Dynamics.

[45] Tian, C. (2018). Firm-level entry and exit dynamics over the business cycles. European Economic Review, $102,298-326$.

[46] Tirole, J. (1985). Asset bubbles and overlapping generations. Econometrica, 53, 1071-1100. 


\section{A Individual's decisions on consumption and investment}

Individuals decide on consumption and investment to maximize the utility (9) subject to the budget constraints (5), (6) and (7), the borrowing constraint (8) and $\kappa_{2, t+1}^{i} \geq 0$. Given that the start-up cost does not depend on $\kappa_{2, t+1}^{i}$, there is a discontinuity in the Lagrangian function. As a consequence, we solve this maximization problem following a two step procedure. First, we obtain the demands of consumption and assets of both savers and entrepreneurs from the first order conditions of the Lagrangian associated to the individuals' maximization problem. Second, we compare the indirect utility function of savers and entrepreneurs to determine the number of entrepreneurs.

Let $\lambda_{1, t}^{i}, \lambda_{2, t+1}^{i}, \lambda_{3, t+2}^{i}, \mu_{t+1}^{i}$ and $\eta_{t+1}^{i}$ be, respectively, the Lagrangian multipliers of individual $i$ associated to (5), (6), (7), (8) and $\kappa_{2, t+1}^{i} \geq 0$. Then, from the first order conditions with respect to $c_{1, t}^{i}, c_{2, t+1}^{i}$, and $c_{3, t+2}^{i}$, we obtain that $\lambda_{1, t}^{i}=\alpha / c_{1, t}^{i}, \lambda_{2, t+1}^{i}=\beta /\left(c_{2, t+1}^{i}-f_{t+1}^{i}\right)$, and $\lambda_{3, t+2}^{i}=\gamma / c_{3, t+2}^{i}$. Next, from the first order conditions with respect to $d_{1 t}^{i}, b_{1 t}^{i}, d_{2 t+1}^{i}$ and $b_{2 t+1}^{i}$, we obtain that $R_{d, t+1}=R_{1, t+1}=R_{2, t+1}=R_{t+1}$ and

$$
\begin{gathered}
\lambda_{1, t}^{i}=\lambda_{2, t+1}^{i} R_{t+1}, \\
\lambda_{2, t+1}^{i}=\left(\lambda_{3, t+2}^{i}+\mu_{t+1}^{i}\right) R_{t+2} .
\end{gathered}
$$

Finally, the first order condition with respect to investment implies

$$
\lambda_{2, t+1}^{i}=q_{t+2}^{i} \lambda_{3, t+2}^{i}+\theta q_{t+2}^{i} \mu_{t+1}^{i}+\eta_{t+1}^{i}
$$

Given that entrepreneurs pay a cost, (40) solves the individuals' maximization problem only when $\kappa_{2, t+1}^{i}>0$.

The solution of the individuals' maximization problem is characterized by the first order conditions (38), (39) and (40) together with the Kuhn-Tucker conditions

$$
\begin{gathered}
\mu_{t+1}^{i}\left[\theta q_{t+2}^{i} \kappa_{2, t+1}^{i}+R_{t+2}\left(b_{2 t+1}^{i}+d_{2 t+1}^{i}\right)\right]=0 \\
\eta_{t+1}^{i} \kappa_{2, t+1}^{i}=0 .
\end{gathered}
$$

We distinguish among four possible solutions. First, if $\eta_{t+1}^{i}>0$ and $\mu_{t+1}^{i}>0$ then (41) and (42) imply $\kappa_{2, t+1}^{i}=0$ and $b_{2 t+1}^{i}+d_{2 t+1}^{i}=0$. The budget constraint $(7)$ implies that $c_{3, t+2}^{i}=0$, which is not a solution of the individuals' maximization problem.

Second, if $\eta_{t+1}^{i}=0$ and $\mu_{t+1}^{i}=0$ then $\kappa_{2, t+1}^{i}>0$ and (39) and (40) imply that $q_{t+2}^{i}=R_{t+2}$, i.e. all assets are perfect substitutes. Because of the start-up cost, the utility obtained when an individual invests in capital will be strictly lower than the level of utility if she does not invest in productive capital. Therefore, $\kappa_{2, t+1}^{i}>0$ cannot be a solution of the individual's maximization problem in this second case. 
Third, if $\eta_{t+1}^{i}>0$ and $\mu_{t+1}^{i}=0$ then (41) and (42) imply that $\kappa_{2, t+1}^{i}=0$ and (38) and (39) imply that $\lambda_{1, t}^{i}=\lambda_{2, t+1}^{i} R_{t+1}$ and $\lambda_{2, t+1}^{i}=\lambda_{3, t+2}^{i} R_{t+2}$. This case characterizes the savers that do not invest in productive capital and are not credit constrained. From the last two equations, we obtain that $c_{2, t+1}^{i}=(\beta / \alpha) c_{1, t}^{i} R_{t+1}$ and $c_{3, t+2}^{i}=(\gamma / \beta) c_{2, t+1}^{i} R_{t+2}$. Combining these two equations with the budget constraints (5)-(7), we obtain (12), (13) in the main text and the optimal consumptions are given by:

$$
\begin{gathered}
c_{1, t}^{i}=\left(\alpha / R_{t+1}\right)\left(R_{t+1} w_{y, t}^{i}+w_{a, t+1}^{i}\right), \\
c_{2, t+1}^{i}=\beta\left(R_{t+1} w_{y, t}^{i}+w_{a, t+1}^{i}\right), \\
c_{3, t+2}^{i}=\gamma R_{t+2}\left(R_{t+1} w_{y, t}^{i}+w_{a, t+1}^{i}\right) .
\end{gathered}
$$

Fourth, if $\eta_{t+1}^{i}=0$ and $\mu_{t+1}^{i}>0$ then (41) and (42) imply that $\kappa_{2, t+1}^{i}>0$ and $\theta q_{t+2}^{i} \kappa_{2, t+1}^{i}+$ $R_{t+2}\left(b_{2 t+1}^{i}+d_{2 t+1}^{i}\right)=0$. Therefore, this case characterizes the entrepreneurs that are credit constrained. We combine (38), (39) and (40) to obtain $\lambda_{1, t}^{i}=\lambda_{2, t+1}^{i} R_{t+1}$ and $\lambda_{2, t+1}^{i}=\psi_{t+2}^{i} q_{t+2}^{i} \lambda_{3, t+2}^{i}$, where $\psi_{t+2}^{i}=$ $(1-\theta) /\left(1-\theta q_{t+2}^{i} / R_{t+2}\right)$. From these two equations and taking into account that entrepreneurs pay the start-up cost, we obtain that $c_{2, t+1}^{i}-f_{t+1}^{i}=(\beta / \alpha) c_{1, t}^{i} R_{t+1}$ and $c_{3, t+2}^{i}=(\gamma / \beta) \psi_{t+2}^{i} q_{t+2}^{i}\left(c_{2, t+1}^{i}-f_{t+1}^{i}\right)$. We note that $\psi_{t+2}^{i}>0$ requires $R_{t+2}>\theta q_{t+2}^{i}$. Combining these last two equations, the binding credit constraint and the budget constraints (5)-(7), we obtain equations (16)-(18) in the main text and consumptions are given by

$$
\begin{gathered}
c_{1, t}^{i, E}=\left(\alpha / R_{t+1}\right)\left(R_{t+1} w_{y, t}^{i}+w_{a, t+1}^{i}-f_{t+1}^{i}\right), \\
c_{2, t+1}^{i, E}=\beta\left(R_{t+1} w_{y, t}^{i}+w_{a, t+1}^{i}-f_{t+1}^{i}\right)+f_{t+1}^{i}, \\
c_{3, t+2}^{i, E}=\gamma \psi_{t+2}^{i} q_{t+2}^{i}\left(R_{t+1} w_{y, t}^{i}+w_{a, t+1}^{i}-f_{t+1}^{i}\right),
\end{gathered}
$$

From the previous analysis, we distinguish between two groups of individuals. First, individuals that do not invest in productive capital and that are not credit constrained. We denote them savers and correspond to the third case. Second, individuals that invest in productive capital and that are credit constrained. We denote them entrepreneurs and correspond to the last case. In what follows, we determine the fraction of each group of individuals in the population. Since the start-up cost introduces a discontinuity, this analysis cannot follow from the first order condition with respect to capital. Instead, we compare the level of utility that an individual that is adult in period $t$ attains as an entrepreneur and as a saver. To this end, we obtain the indirect utility functions of both agents by substituting in the utility function, (9), the optimal consumption demands of savers, (43)-(45), and of entrepreneurs, (46)-(48). We obtain that the indirect utility function when the individual is a saver is

$$
u_{t-1}^{i, S}=\ln \left(w_{t}^{i}+R_{t} w_{t-1}^{i}\right)-\alpha \ln R_{t}+\gamma \ln R_{t+1}+v
$$


where

$$
v=\ln (\alpha)^{\alpha}+\ln (\beta)^{\beta}+\ln (\gamma)^{\gamma} .
$$

The indirect utility of the same individual when she is an entrepreneur is

$$
u_{t-1}^{i, E}=\ln \left(w_{t}^{i}+R_{t} w_{t-1}^{i}-f_{t}^{i}\right)-\alpha \ln R_{t}+\gamma \ln \left(\psi_{t+1}^{i} q_{t+1}^{i}\right)+v .
$$

This individual decides to be an entrepreneur if $u_{t-1}^{i, E} \geq u_{t-1}^{i, S}$, which happens when $q_{t+1}^{i} \geq R_{t+1} / \omega_{t}^{i}$, where $\omega_{t}^{i}$ is defined in (19) in the main text. Remember that $q_{t+1}^{i}<R_{t+1} / \theta$. This inequality is compatible with $q_{t+1}^{i} \geq R_{t+1} / \omega_{t}^{i}$ because $\omega_{t}^{i} \in(\theta, 1)$ but implies an upper bound for $q_{t+1}^{i}$. This upper bound is introduced in Assumption B.

\section{B Total factor productivity}

In this appendix, we show how TFP depends on $\bar{\delta}_{t}$ and on $z_{t}$. To this end, we rewrite (37) as

$$
p_{t}=A \frac{z_{t} \int_{\delta_{t}}^{\delta_{\max }} \delta g^{1}(\delta) d \delta+(1-\xi) \phi \int_{\delta_{t}}^{\delta_{\max }} \delta g^{2}(\delta) d \delta}{z_{t} \int_{\delta_{t}}^{\delta_{\max }} g^{1}(\delta) d \delta+(1-\xi) \phi \int_{\delta_{t}}^{\delta_{\max }} g^{2}(\delta) d \delta},
$$

where

$$
g^{j}(\delta)=\frac{\delta^{v_{j}} f(\delta)}{1-\theta s A \delta / R_{t+1}} \text { for all } j=1,2
$$

We first obtain

$$
\begin{aligned}
\frac{\partial p_{t}}{\partial \bar{\delta}_{t}=}- & \frac{A}{\left(z \int_{\delta_{t}}^{\delta_{\max }} g^{1}(\delta) d \delta+(1-\xi) \phi \int_{\delta_{t}}^{\delta_{\max }} g^{2}(\delta) d \delta\right)^{2}} \\
\times & \left\{\begin{array}{c}
{\left[z \bar{\delta} g^{1}\left(\bar{\delta}_{t}\right)+(1-\xi) \phi \bar{\delta} g^{2}\left(\bar{\delta}_{t}\right)\right] \times} \\
\times\left[z \int_{\bar{\delta}_{t}}^{\delta_{\max }} g^{1}(\delta) d \delta+\phi(1-\xi) \int_{\bar{\delta}_{t}}^{\delta_{\max }} g^{2}(\delta) d \delta\right] \\
-\left[z g^{1}\left(\bar{\delta}_{t}\right)+(1-\xi) \phi g^{2}\left(\bar{\delta}_{t}\right)\right] \\
\times\left[z \int_{\bar{\delta}_{t}}^{\delta_{\max }} \delta g^{1}(\delta) d \delta+\phi(1-\xi) \int_{\delta_{t}}^{\delta_{\max }} \delta g^{2}(\delta) d \delta\right]
\end{array}\right\},
\end{aligned}
$$

which can be rewritten as

$$
\begin{aligned}
& \frac{\partial p_{t}}{\partial \bar{\delta}_{t+1}}=-\frac{A\left[z g^{1}\left(\bar{\delta}_{t}\right)+(1-\xi) \phi g^{2}\left(\bar{\delta}_{t}\right)\right]}{\left(z \int_{\bar{\delta}_{t}}^{\delta_{\max }} g^{1}(\delta) d \delta+(1-\xi) \phi \int_{\bar{\delta}_{t}}^{\delta_{\max }} g^{2}(\delta) d \delta\right)^{2}} \\
& \times\left\{\begin{array}{c}
{\left[z \int_{\bar{\delta}_{t}}^{\delta_{\max }} \bar{\delta}_{t} g^{1}(\delta) d \delta+\phi(1-\xi) \int_{\bar{\delta}_{t}}^{\delta_{\max }} \bar{\delta}_{t} g^{2}(\delta) d \delta\right]} \\
-\left[z \int_{\bar{\delta}_{t}}^{\delta_{\max }} \delta g^{1}(\delta) d \delta+\phi(1-\xi) \int_{\bar{\delta}_{t}}^{\delta_{\max }} \delta g^{2}(\delta) d \delta\right]
\end{array}\right\}>0 .
\end{aligned}
$$

Indeed, the last term into the brackets is negative because the values of $\delta$ considered are larger or equal to $\bar{\delta}$. 
We next obtain

$$
\frac{\partial p_{t}}{\partial z_{t}}=A(1-\xi) \phi \frac{\int_{\bar{\delta}_{t}}^{\delta_{\max }} \delta g^{1}(\delta) d \delta \int_{\bar{\delta}_{t}}^{\delta_{\max }} g^{2}(\delta) d \delta-\int_{\bar{\delta}_{t}}^{\delta_{\max }} g^{1}(\delta) d \delta \int_{\bar{\delta}_{t}}^{\delta_{\max }} \delta g^{2}(\delta) d \delta}{\left(z \int_{\bar{\delta}_{t}}^{\delta_{\max }} g^{1}(\delta) d \delta+(1-\xi) \phi \int_{\bar{\delta}_{t}}^{\delta_{\max }} g^{2}(\delta) d \delta\right)^{2}},
$$

which is positive if

$$
\int_{\bar{\delta}_{t}}^{\delta_{\max }} \delta g^{1}(\delta) d \delta \int_{\bar{\delta}_{t}}^{\delta_{\max }} g^{2}(\delta) d \delta-\int_{\bar{\delta}_{t}}^{\delta_{\max }} g^{1}(\delta) d \delta \int_{\bar{\delta}_{t}}^{\delta_{\max }} \delta g^{2}(\delta) d \delta>0 .
$$

After some manipulation, we can rewrite the former inequality as

$$
\int_{\bar{\delta}_{t}}^{\delta_{\max }} \int_{\bar{\delta}_{t}}^{\delta_{\max }} g^{1}\left(\delta^{j}\right) g^{2}\left(\delta^{i}\right)\left(\delta^{j}-\delta^{i}\right) d \delta^{i} d \delta^{j}>0
$$

which is equivalent to

$$
\begin{aligned}
& \int_{\delta^{i}}^{\delta_{\max }} \int_{\bar{\delta}_{t}}^{\delta_{\max }} g^{1}\left(\delta^{j}\right) g^{2}\left(\delta^{i}\right)\left(\delta^{j}-\delta^{i}\right) d \delta^{i} d \delta^{j}+ \\
& \int_{\bar{\delta}_{t}}^{\delta^{i}} \int_{\bar{\delta}_{t}}^{\delta_{\max }} g^{1}\left(\delta^{j}\right) g^{2}\left(\delta^{i}\right)\left(\delta^{j}-\delta^{i}\right) d \delta^{i} d \delta^{j}>0 .
\end{aligned}
$$

In (49), we split the inequality in two parts. In the first one, $\delta^{j}>\delta^{i}$ and in the second $\delta^{j}<\delta^{i}$. Using this same separation, we deduce that

$$
\begin{aligned}
& \int_{\bar{\delta}_{t}}^{\delta^{i}} \int_{\bar{\delta}_{t}}^{\delta_{\max }} g^{1}\left(\delta^{j}\right) g^{2}\left(\delta^{i}\right)\left(\delta^{j}-\delta^{i}\right) d \delta^{i} d \delta^{j} \\
= & -\int_{\delta^{i}}^{\delta_{\max }} \int_{\bar{\delta}_{t}}^{\delta_{\max }} g^{2}\left(\delta^{j}\right) g^{1}\left(\delta^{i}\right)\left(\delta^{j}-\delta^{i}\right) d \delta^{i} d \delta^{j}
\end{aligned}
$$

We use (50) to rewrite (49) as the following inequality in which $\delta^{j}>\delta^{i}$ :

$$
\begin{gathered}
\int_{\delta^{i}}^{\delta_{\max }} \int_{\bar{\delta}_{t}}^{\delta_{\max }} g^{1}\left(\delta^{j}\right) g^{2}\left(\delta^{i}\right)\left(\delta^{j}-\delta^{i}\right) d \delta^{i} d \delta^{j} \\
-\int_{\delta^{i}}^{\delta_{\max }} \int_{\bar{\delta}_{t}}^{\delta_{\max }} g^{2}\left(\delta^{j}\right) g^{1}\left(\delta^{i}\right)\left(\delta^{j}-\delta^{i}\right) d \delta^{i} d \delta^{j}>0 .
\end{gathered}
$$

Using the expression of $g^{j}(\delta)$, we rewrite the former inequality as

$$
\int_{\delta^{i}}^{\delta_{\max }} \int_{\bar{\delta}_{t}}^{\delta_{\max }}\left(\frac{f\left(\delta^{i}\right)}{1-\theta s A \delta^{i} / R_{t+1}}\right)^{2}\left(\delta^{i}\right)^{v_{1}+v_{2}}\left(\delta^{j}-\delta^{i}\right)\left[\left(\frac{\delta^{j}}{\delta^{i}}\right)^{v_{1}}-\left(\frac{\delta^{j}}{\delta^{i}}\right)^{v_{2}}\right] d \delta^{i} d \delta^{j}>0 .
$$

Since $\delta^{j}>\delta^{i}$, we deduce that the inequality holds if and only if $v_{1}>v_{2}$. This proves that $\partial p_{t} / \partial z_{t}>0$ if and only if $v_{1}>v_{2}$.

\section{Supplementary material}

An online appendix with supplementary material associated with this article is available at https://sites.google.com/view/x raurich. 